\title{
Dynamic Characterization of Crystalline Supramolecular Rotors Assembled through Halogen-Bonding
}

Luca Catalano, ${ }^{1}$ Salvador Pérez-Estrada, ${ }^{2}$ Giancarlo Terraneo, ${ }^{1}$ Tullio Pilati, ${ }_{2}$ Giuseppe Resnati, ${ }^{1}$ Pierangelo Metrangolo, ${ }^{1,3}$ and Miguel A. Garcia-Garibay ${ }^{2}$

${ }^{1}$ Laboratory of Nanostructured Fluorinated Materials (NFMLab), Department of Chemistry, Materials, and Chemical Engineering "Giulio Natta", Politecnico di Milano, via L. Mancinelli 7, 20131 Milano, Italy;.

${ }^{2}$ Department of Chemistry and Biochemistry, University of California, Los Angeles, California 90095-1569, USA; ${ }^{3}$ VTT-Technical Research Centre of Finland, PO Box 1000, Espoo FI-02044, Finland.

E-mail: giancarlo.terraneo@polimi.it; mgg@chem.ucla.edu; pierangelo.metrangolo@polimi.it 


\section{Contents}

$\begin{array}{ll}\text { 1. General Information } & \text { S4 }\end{array}$

$\begin{array}{ll}\text { 2. ATR-FTIR spectroscopy analysis } & \text { S4 }\end{array}$

$\begin{array}{ll}\text { 3. X-ray single crystal analysis } & \text { S4 }\end{array}$

$\begin{array}{ll}\text { 4. X-Ray powder diffraction } & \text { S4 }\end{array}$

$\begin{array}{ll}\text { 5. Spin lattice relaxation experiments (T1, NMR) } & \text { S4 }\end{array}$

$\begin{array}{ll}\text { 6. Variable Temperature Solid State 2H NMR } & \text { S5 }\end{array}$

7. Synthesis of DABCO-d $d_{12} \quad$ S5

\section{List of Tables}

Table S1. Co-crystals melting points. $\quad$ S12

Table S2. Halogen bonding and hydrogen bonding geometrical features. $\quad$ S33

Table S3. Crystallographic details of $2 \mathbf{e}$ data collections at 7 different temperature. $\quad$ S36

Table S4. Crystallographic details of $\mathbf{2 b}$ and $\mathbf{2 c}$ data collections at different temperatures. $\quad$ S37

Table S5. Crystallographic details of $\mathbf{2 a}$ and $\mathbf{2 d}$ data collections at different temperatures $\quad$ S38

\section{List of Figures}

Figure S1. DABCO ATR-FTIR spectrum. $\quad$ S6

Figure S2. para-fluoroiodobenzene (1a) ATR-FTIR spectrum. $\quad$ S7

Figure S3. Co-crystal of 2a ATR-FTIR spectrum. $\quad$ S7

Figure S4. 2,6-difluoroiodobenzene (1b) ATR-FTIR spectrum. $\quad$ S8

Figure S5. Co-crystal of 2b ATR-FTIR spectrum. $\quad$ S8

Figure S6. 2,6-difluoroiodobenzene (1c) ATR-FTIR spectrum $\quad$ S9

Figure S7. Co-crystal of 2c ATR-FTIR spectrum. $\quad$ S9

$\begin{array}{ll}\text { Figure S8. 3,4,5-trifluoroiodobenzene (1d) ATR-FTIR spectrum. } & \text { S10 }\end{array}$

Figure S9. Co-crystal of 2d ATR-FTIR spectrum. $\quad$ S10

$\begin{array}{ll}\text { Figure S10. Pentafluoroiodobenzene (1e) ATR-FTIR spectrum. } & \text { S11 }\end{array}$

Figure S11. Co-crystal of 2e ATR-FTIR spectrum. $\quad$ S11

Figure S12. Comparison between calculated (bottom) and experimental (top) powder X-ray diffraction

patterns of complex 2a. $\quad \mathrm{S} 12$

Figure S13. Comparison between calculated (bottom) and experimental (top) powder X-ray diffraction patterns of complex $\mathbf{2 b}$. $\quad \mathrm{S} 13$

Figure S14. Comparison between calculated (bottom) and experimental (top) powder X-ray diffraction patterns of complex 2c. $\quad$ S13

Figure S15. Comparison between calculated (bottom) and experimental (top) powder X-ray diffraction patterns of complex $\mathbf{2 d}$. $\quad \mathrm{S} 14$

Figure S16. Comparison between calculated (bottom) and experimental (top) powder X-ray diffraction

patterns of complex $2 \mathbf{e} . \quad$ S14 
Figure S17. ${ }^{1} \mathrm{H}$ spin-lattice relaxation times $\left({ }^{1} \mathrm{H} \mathrm{T}_{1}\right)$ measured on $4-\mathrm{FPhI} \cdot$ dabco $(2 \mathrm{a})$ from $310 \mathrm{~K}-200 \mathrm{~K}$ at $300 \mathrm{MHz}$ (solid blue circles).

Figure S18. ${ }^{1} \mathrm{H}$ spin-lattice relaxation times $\left({ }^{1} \mathrm{H} \mathrm{T}_{1}\right)$ measured on $2,6-\mathrm{F}_{2} \mathrm{PhI} \cdot \mathrm{dabco}(\mathbf{2 b})$ from $295 \mathrm{~K}-145 \mathrm{~K}$ at $300 \mathrm{MHz}$ (solid blue circles).

Figure S19. ${ }^{1} \mathrm{H}$ spin-lattice relaxation times $\left({ }^{1} \mathrm{H} \mathrm{T}_{1}\right)$ measured on 3,5- $\mathrm{F}_{2} \mathrm{PhI} \cdot \mathrm{dabco}(\mathbf{2 c})$ from $196 \mathrm{~K}-146 \mathrm{~K}$ at $300 \mathrm{MHz}$.

Figure 20. ${ }^{1} \mathrm{H}$ spin-lattice relaxation times $\left({ }^{1} \mathrm{H} \mathrm{T}_{1}\right)$ measured on $3,4,5-\mathrm{F}_{3} \mathrm{PhI} \cdot$ dabco $(\mathbf{2 d})$ from $296 \mathrm{~K}-150 \mathrm{~K}$ at $300 \mathrm{MHz}$ (solid blue circles).

Figure S21 Representative ${ }^{1} \mathrm{H}$ wideline spin-lattice relaxtion $\left(\mathrm{T}_{1}\right)$ NMR measurement via the saturationrecovery method at $290 \mathrm{~K}$ : stacked spectra (left) and overlaid spectra (right).

Figure S22. Representative example of the mono-exponential fit to representative ${ }^{1} \mathrm{H}$ wideline spin-lattice relaxation $\left(T_{1}\right)$ saturation recovery data of complex $2 \mathrm{a}$ at $\mathrm{T}=290 \mathrm{~K}$.

Figure S23. Representative ${ }^{1} \mathrm{H}$ wideline spin-lattice relaxtion $\left(\mathrm{T}_{1}\right)$ NMR measurement via the saturationrecovery method at $295 \mathrm{~K}$ : stacked spectra (left) and overlaid spectra (right).

Figure S24. Representative example of the mono-exponential fit to representative ${ }^{1} \mathrm{H}$ wideline spin-lattice relaxation $\left(\mathrm{T}_{1}\right)$ saturation recovery data of complex $2 \mathrm{~b}$ at $\mathrm{T}=295 \mathrm{~K}$

Figure S25. Representative ${ }^{1} \mathrm{H}$ wideline spin-lattice relaxtion $\left(\mathrm{T}_{1}\right)$ NMR measurement via the saturationrecovery method at $296 \mathrm{~K}$ : stacked spectra (left) and overlaid spectra (right).

S21

Figure S26. Representative example of the mono-exponential fit to representative ${ }^{1} \mathrm{H}$ wideline spin-lattice relaxation $\left(\mathrm{T}_{1}\right)$ saturation recovery data of complex $2 \mathrm{c}$ at $\mathrm{T}=296 \mathrm{~K}$.

Figure S27. Representative ${ }^{1} \mathrm{H}$ wideline spin-lattice relaxtion $\left(\mathrm{T}_{1}\right)$ NMR measurement via the saturationrecovery method at $295 \mathrm{~K}$ : stacked spectra (left) and overlaid spectra (right).

Figure S28. Representative example of the mono-exponential fit to representative ${ }^{1} \mathrm{H}$ wideline spin-lattice relaxation $\left(T_{1}\right)$ saturation recovery data of complex $2 \mathrm{~d}$ at $\mathrm{T}=296 \mathrm{~K}$.

Figure S29. Representative ${ }^{1} \mathrm{H}$ wideline spin-lattice relaxtion $\left(\mathrm{T}_{1}\right)$ NMR measurement via the saturationrecovery method at $275 \mathrm{~K}$ : stacked spectra (left) and overlaid spectra (right).

Figure S30. Representative example of the mono-exponential fit to representative ${ }^{1} \mathrm{H}$ wideline spin-lattice relaxation $\left(T_{1}\right)$ saturation recovery data of complex $2 \mathrm{e}$ at $\mathrm{T}=275 \mathrm{~K}$.

Figure S31. Variable temperature ${ }^{2} \mathrm{H}$ NMR quadrupolar echo experiments for complex FPhI·DABCO- $d_{12}$ $\left(\mathbf{2 a}-\boldsymbol{d}_{12}\right)$ from $295 \mathrm{~K}$ to $150 \mathrm{~K}$.

Figure S32. Experimental and simulated ${ }^{2} \mathrm{H}$ NMR quadrupolar echo spectra of 2a- $\boldsymbol{d}_{12}$.

Figure S33. Variable temperature ${ }^{2} \mathrm{H}$ NMR quadrupolar echo experiments for complex $\mathrm{F}_{2} \mathrm{PhI} \cdot \mathrm{DABCO}-d_{12}$ $\left(\mathbf{2 b}-\boldsymbol{d}_{12}\right)$ from $295 \mathrm{~K}$ to $140 \mathrm{~K}$.

Figure S35. Variable temperature ${ }^{2} \mathrm{H}$ NMR quadrupolar echo experiments for complex $\mathrm{F}_{5} \mathrm{PhI} \cdot \mathrm{DABCO}-d_{12}$ (2e-d $\boldsymbol{d}_{12}$ ) from $295 \mathrm{~K}$ to $155 \mathrm{~K}$. 
General Information. All reactions were carried out under an inert atmosphere of argon in oven or flame-dried glassware, unless the reaction procedure states otherwise. All chemicals were purchased from commercial suppliers and used as received. Uncorrected melting points were recorded on a melting point apparatus using sealed glass capillaries. Carbon-13 magnetic resonance spectra were recorded at $125 \mathrm{MHz}$. All chemical shifts are reported in ppm on the $\delta$-scale relative to TMS $(\delta 0.0)$ using residual solvent as reference $\left(\mathrm{CDCl}_{3} \delta 77.16\right.$ for carbon). ${ }^{1} \mathrm{H}$ magnetic resonance spectra were recorded at $400 \mathrm{MHz}$ and collected in $\mathrm{CDCl}_{3}$ solutions using $\mathrm{CF}_{3} \mathrm{CH}_{2} \mathrm{OCH}_{2} \mathrm{CF}_{3}$ as internal reference. High resolution mass spectrometric data were collected using Electrospray Ionization technique with a Time-of-Flight detector (ESI-TOF) mass spectrometer and a Liquid Introduction Field Desorption Ionization mass spectrometer with a Time-of-Flight detector (LIFDITOF).

ATR-FTIR spectroscopy analysis. IR spectra were obtained using a Nicolet iS50 FTIR spectrometer equipment with ATR device. Units are reported in $\mathrm{cm}-1$. For each compound the spectra were collected with the following set up: 32 scans in the region $400-4000 \mathrm{~cm}^{-1}$ with $\mathrm{KBr}$ beamsplitter. All the spectra have an accuracy of $\pm 4 \mathrm{~cm}^{-1}$.

X-ray single crystal analysis. The co-crystals were synthesized by directly mixing the iodobenzene derivatives and $\mathrm{DABCO}$ in a 2:1 molar ratio, except $2 \mathrm{c}$ with 1:1 molar ratio, in acetone at room temperature. The obtained solutions were put into open vials and left slow evaporating in a closed jar containing mineral oil. For all the products colorless prismatic crystals were obtained. The crystals were measured using Mo-K $\alpha$ radiation on a Bruker KAPPA APEX II diffractometer with a Bruker KRYOFLEX low temperature device. The crystal structures were solved by direct method and refined against F2 using SHELXL97 ${ }^{1}$ Packing diagrams were generated using Mercury 3.5.1. ${ }^{2}$ The non-hydrogen atoms were refined anisotropically and hydrogen atoms were refined using difference Fourier map or positioned geometrically. The phase transition was measured cooling and heating the systems and measuring the temperature at which changes occur to the diffraction pattern.

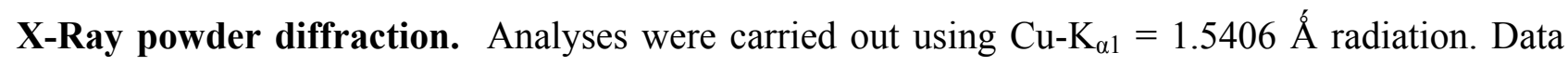
were collected at room temperature in the range of $2 \Theta=4-50^{\circ}$ (step of $0.016^{\circ}$, step time $0.125 \mathrm{~s}$ ).

Spin lattice relaxation experiments (T1, NMR). 1H T1, NMR relaxation was measured on polycrystalline samples of complex F5PhI·DABCO (1) obtained from crystallization of a solution in acetone of pentafluoroiodobenzene and DABCO in a 2:1 molar ratio. The sample was placed 
inside a borosilicate glass NMR tube between two glass rods and then, prior to sealing under vacuum, the sample was vacuumed-argon backfilled (x2). The experiments were carried out with a static wideline probe using solid-state spectrometer operating at a $1 \mathrm{H}$ Larmor frequency of 300 MHz. The saturation recovery sequence used contains a saturation pulse comb followed by a time $\tau$ ' ( $\tau$ ' values taken from the variable delay list) with a $\pi / 2$ pulse p1. For each measurement, an acquisition time of $2.0985 \mathrm{~ms}$ was used. The $1 \mathrm{H}$ spin-lattice relaxation experiments were determined for $\mathrm{T}=141 \mathrm{~K}-295 \mathrm{~K}$.

Variable Temperature Solid State 2H NMR. 2H NMR experiments were performed on polycrystalline samples of $\mathbf{2 a}, \mathbf{2} \mathbf{b}$ and $\mathbf{2} \mathbf{d}$ obtained from crystallization of a solution in acetone of the iodobenzene derivatives and DABCO-d12 in a 2:1 molar ratio. Solid state $2 \mathrm{H}$ NMR experiments were recorded on a Bruker300 spectrometer operating at a frequency of $46.07 \mathrm{MHz}$, using a $4 \mathrm{~mm}$ wide-line probe with a $2 / \pi$ pulse of $2.5 \mu \mathrm{s}$. A quadrupolar-echo pulse sequence with phase-cycling along with an echo delay of $50 \mu$ s and recycle delay of $10 \mathrm{~s}$ was employed to acquire the $2 \mathrm{H}$ wide-line spectra. Variable temperature experiments were recorded in the range of $140 \mathrm{~K}-$ $295 \mathrm{~K}$ and the temperature inside the probe was calibrated by using the shift of ${ }^{207} \mathrm{~Pb}$ as reference. The spectra were acquired by averaging at least 32 scans and processed with a line broadening of 5 $\mathrm{kHz}$.

\section{Synthesis of DABCO- $d_{12}$}

\section{Reaction Scheme:}

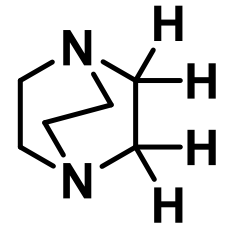

DABCO

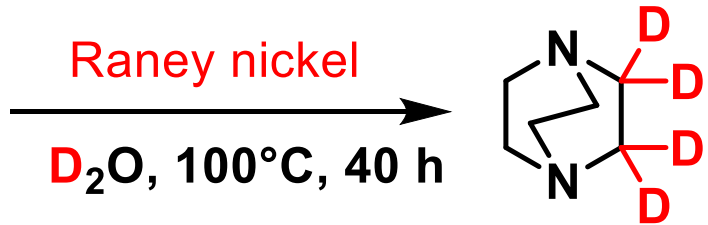

DABCO- $d_{12}$

Step 1. Preparation of Raney-nickel containing active deuterium. A round bottom flask containing deuterium oxide $(7.5 \mathrm{~mL})$ was cooled on an iced bath, then while stirring, sodium metal $(1.14 \mathrm{~g})$ was carefully added in small portions so that the exothermic reaction can be safely controlled. After the addition of sodium was complete, the resulting solution was stirred at room temperature and then heated at $50{ }^{\circ} \mathrm{C}$. Thereafter, nickel-aluminum alloy (Raney-nickel nonactivated, 1,5 g) was added in small portions so that the temperature did not raise above $55^{\circ} \mathrm{C}$ with each addition. After the addition was complete, the resulting slurry was heated at $50^{\circ} \mathrm{C}$ for $1 \mathrm{~h}$ and 
the supernatant solution was decanted. Then the remaining solid was rinsed with deuterium oxide (5 x $3 \mathrm{~mL}$ ).

Step 2. Hydrogen-deuterium exchange cycle. To the resulting black-gray slurry, 1,4diazabicyclo[2.2.2] octane $(409 \mathrm{mg})$ and deuterium oxide $(1.5 \mathrm{~mL})$ were added. The resulting mixture was heated at $100^{\circ} \mathrm{C}$ for $40 \mathrm{~h}$ and then cooled to room temperature. The liquid supernatant was then decanted and the solids were washed with water $(3 \times 10 \mathrm{~mL})$. The organics were extracted from the aqueous residue with dichloromethane $(4 \times 15 \mathrm{~mL})$. The combined organic layers were dried over $\mathrm{MgSO}_{4}$ and the solvent was carefully evaporated at $30{ }^{\circ} \mathrm{C}$ under vacuum. The solid residue was sublimated under vacuum to afford dabco- $d_{12}$ (ca. $100 \mathrm{mg}$, ca. $25 \%$ ) as white crystals. m.p. $111-114{ }^{\circ} \mathrm{C} . \mathrm{MS}(\mathrm{ESI}):[\mathrm{M}+\mathrm{H}]^{+}: 123.17\left(\mathrm{D}_{10}, 1.9 \%\right), 124.18\left(\mathrm{D}_{11}, 28.2 \%\right), 125.18\left(\mathrm{D}_{12}, 100 \%\right)$, accounting for $88 \%$ deuterium atom content. IR (neat) $v_{\max }: 3397,3236,2229,2121,1678,1165$, 1135, 927, 882691. $\left.{ }^{13} \mathrm{C} \mathrm{NMR} \mathrm{(125} \mathrm{MHz,} \mathrm{CDCl}_{3}\right) \delta 45.8$ (pent, $J_{C D}=21.0 \mathrm{~Hz}$ ).

\section{Figures and Tables:}

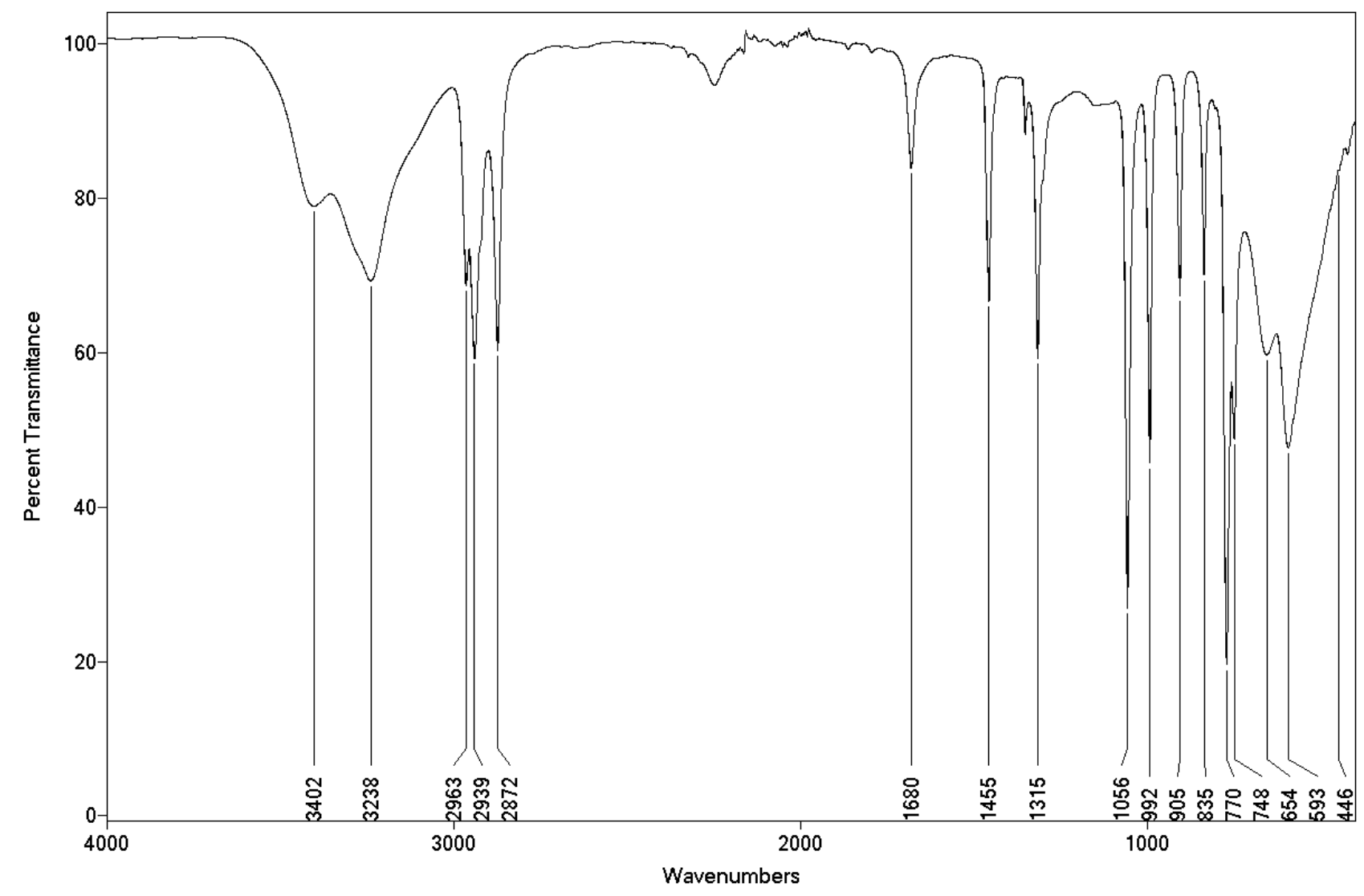

Figure S1. DABCO ATR-FTIR spectrum. 


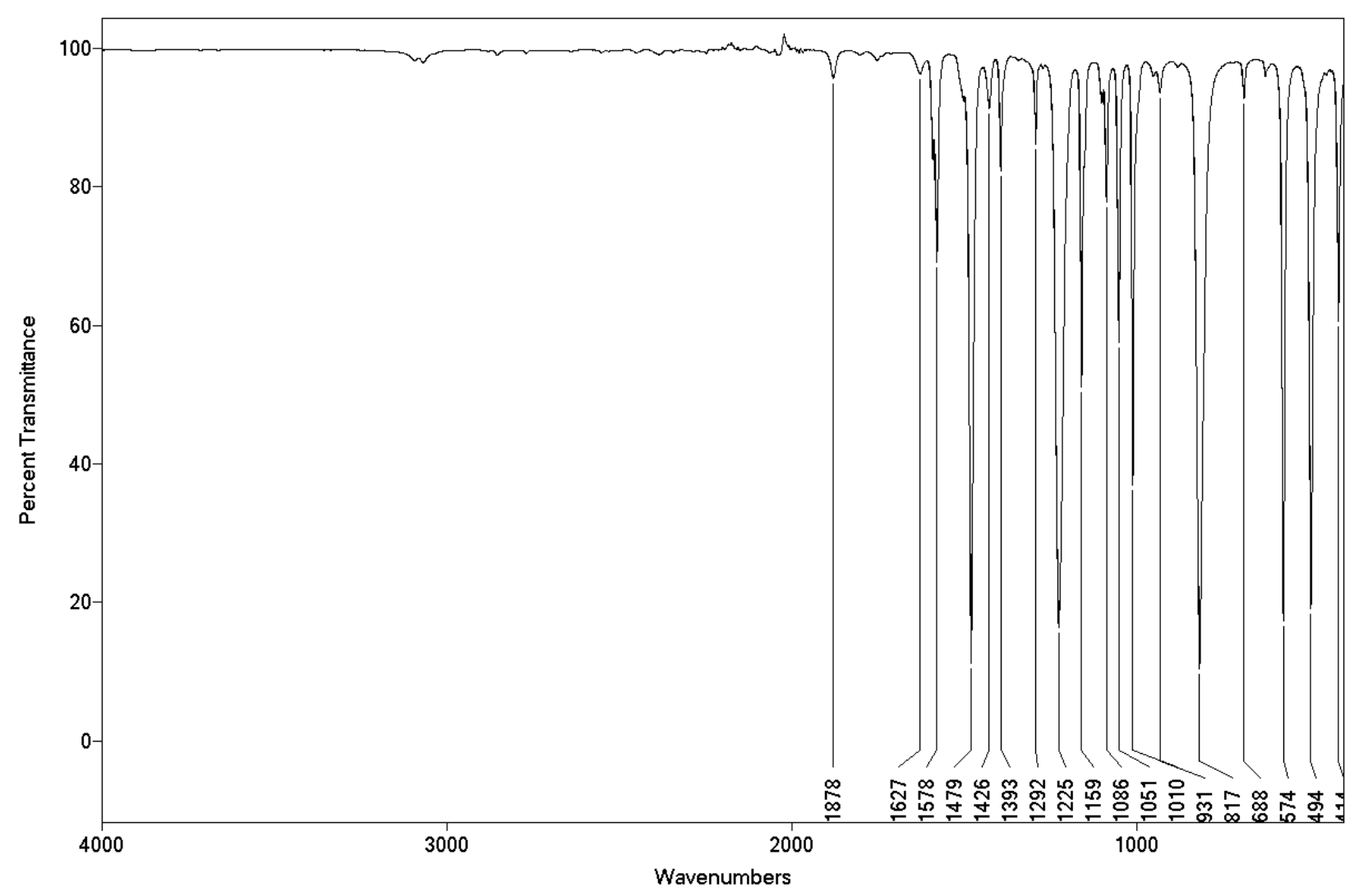

Figure S2. para-fluoroiodobenzene (1a) ATR-FTIR spectrum.

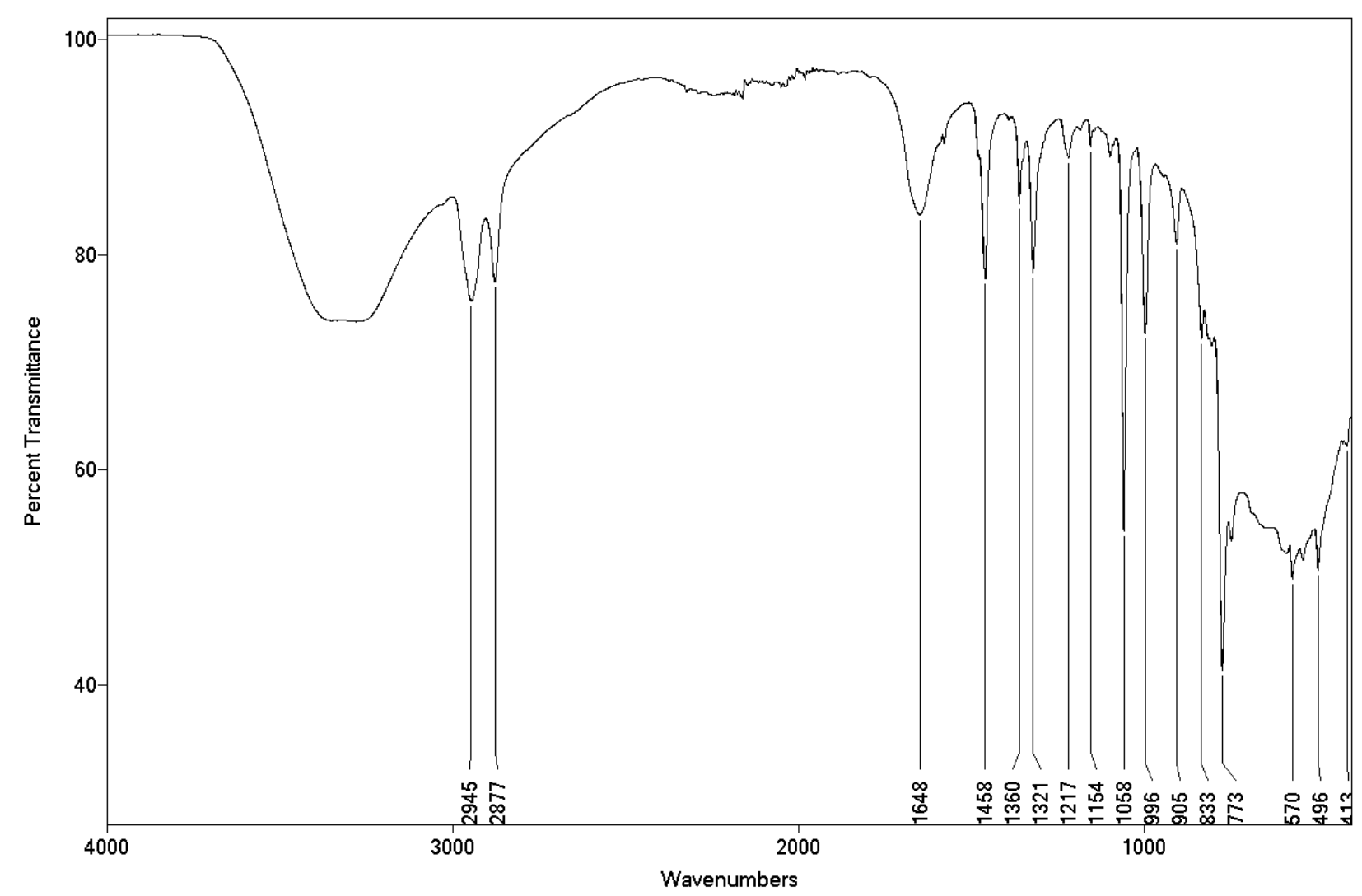

Figure S3. Co-crystal of 2a ATR-FTIR spectrum. 


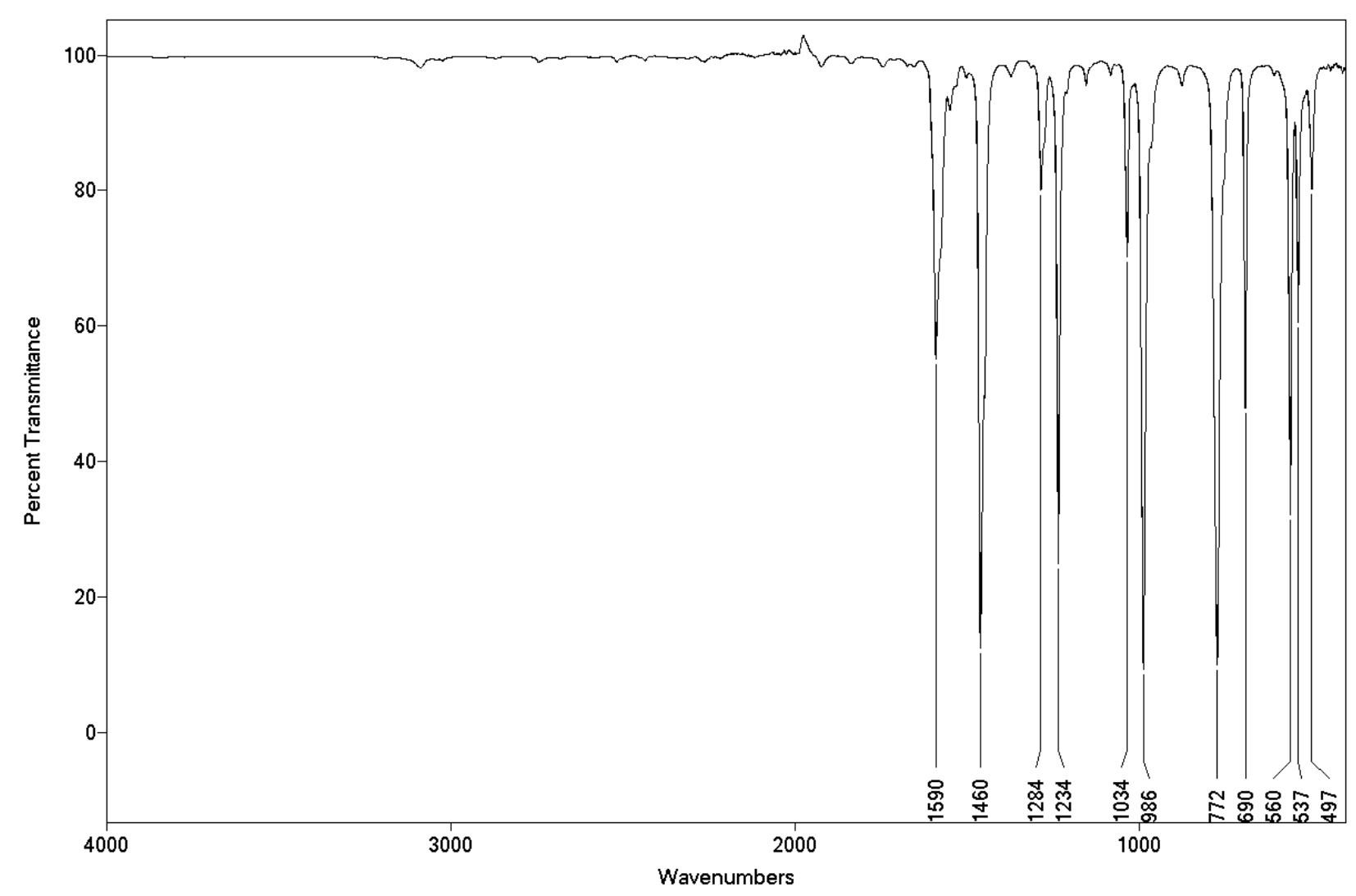

Figure S4. 2,6-difluoroiodobenzene (1b) ATR-FTIR spectrum.

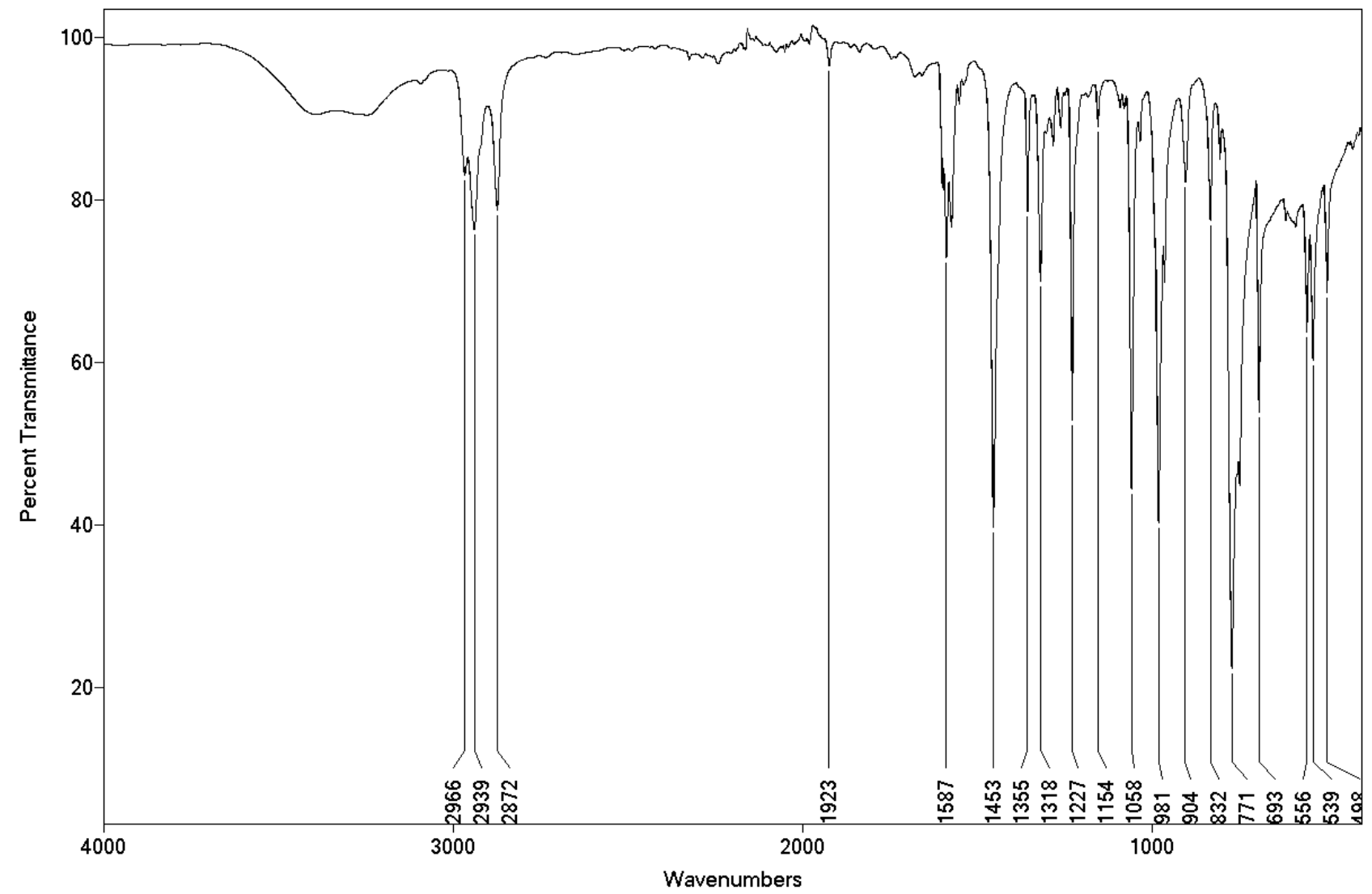

Figure S5. Co-crystal of 2b ATR-FTIR spectrum. 


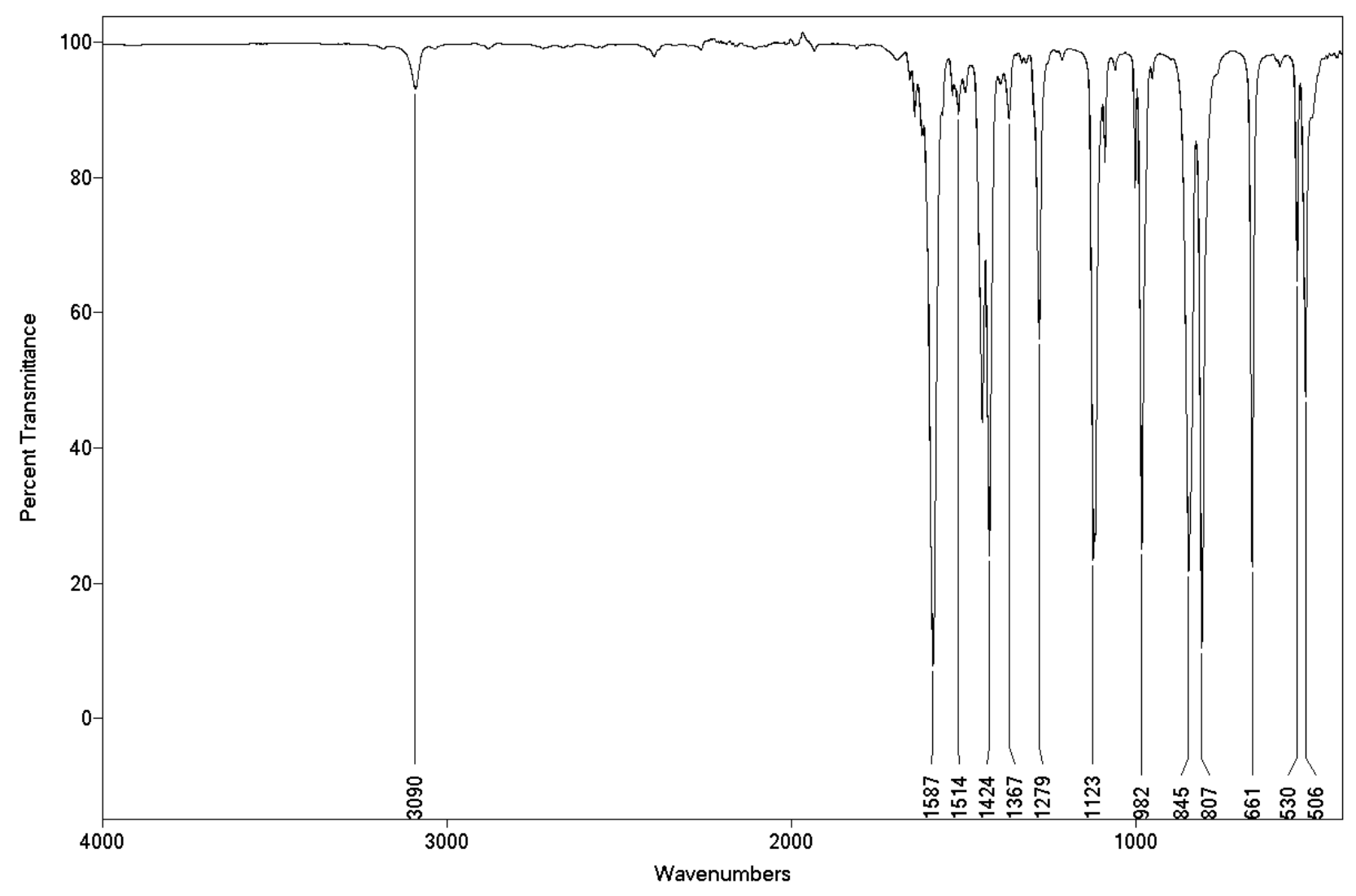

Figure S6. 2,6-difluoroiodobenzene (1c) ATR-FTIR spectrum.

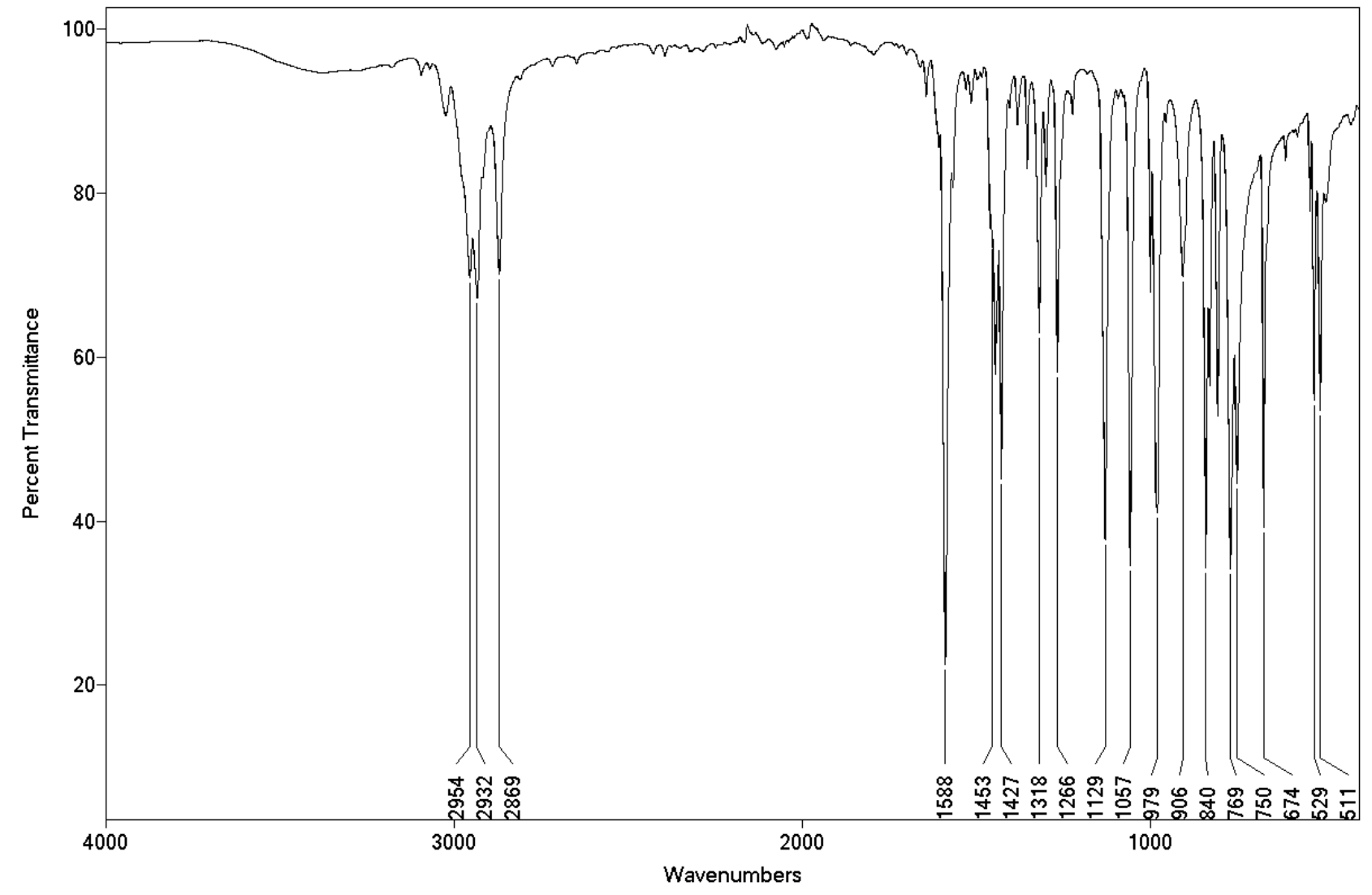

Figure S7. Co-crystal of 2c ATR-FTIR spectrum. 


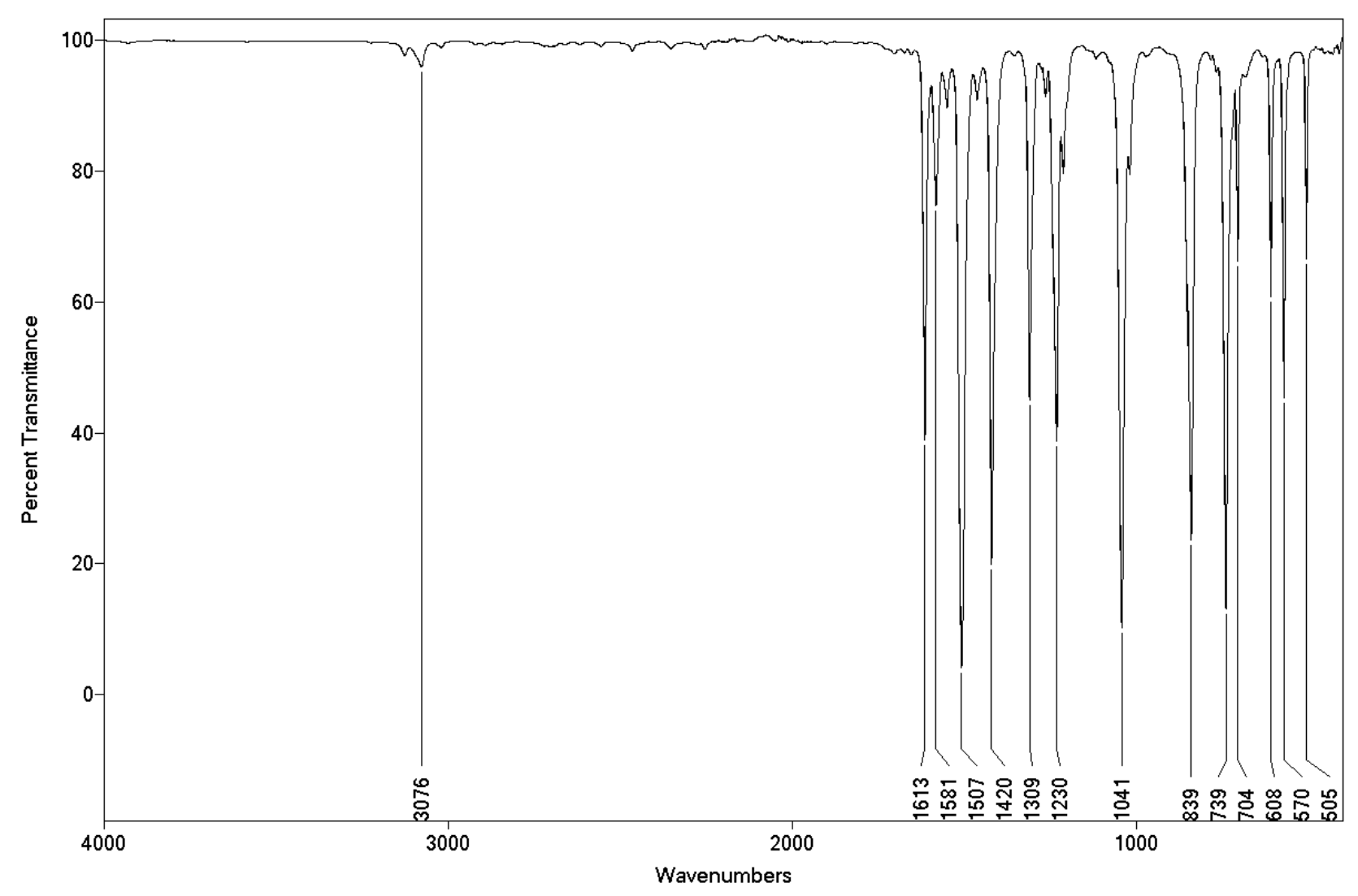

Figure S8. 3,4,5-trifluoroiodobenzene (1d) ATR-FTIR spectrum.

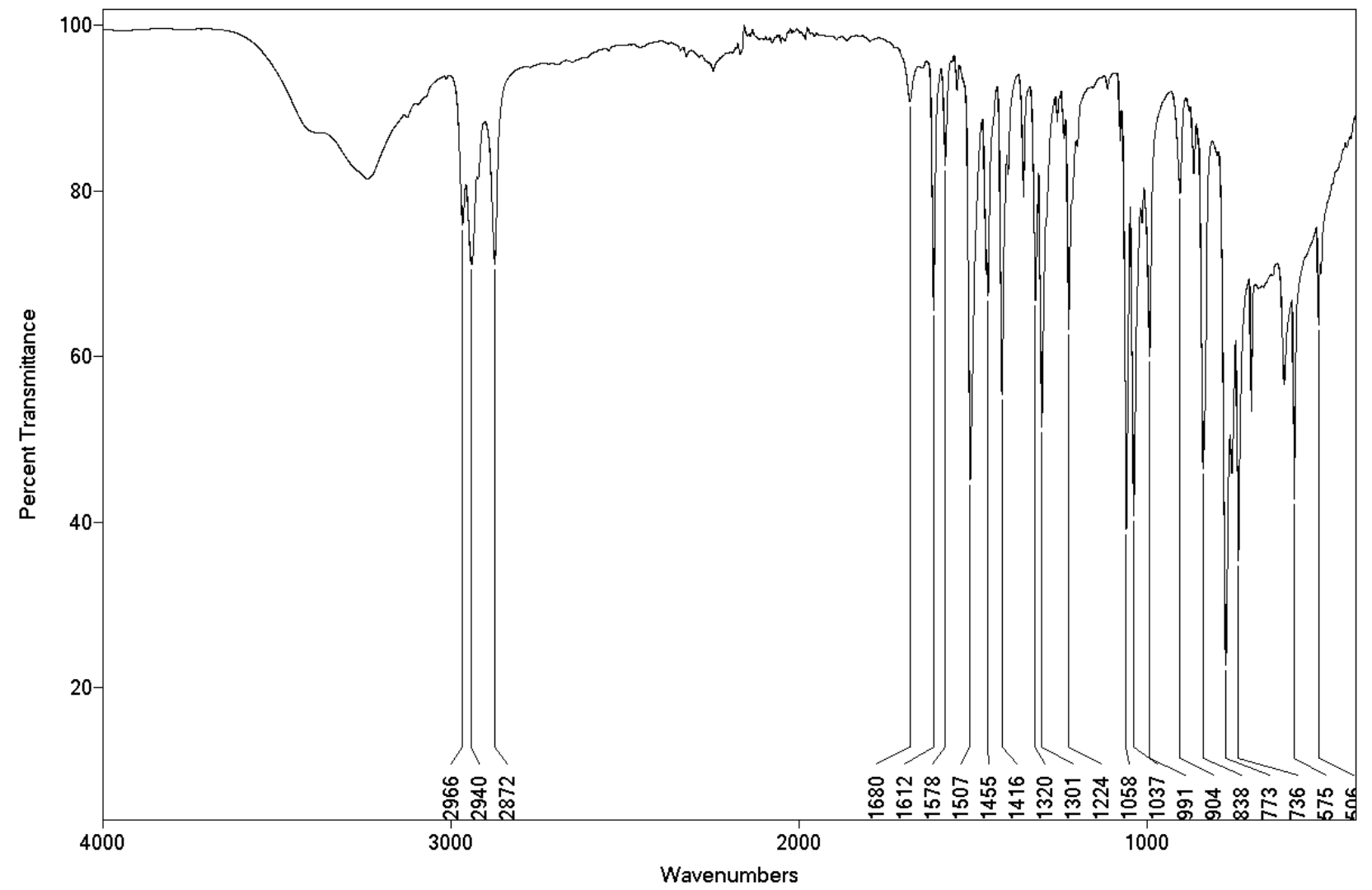

Figure S9. Co-crystal of 2d ATR-FTIR spectrum. 


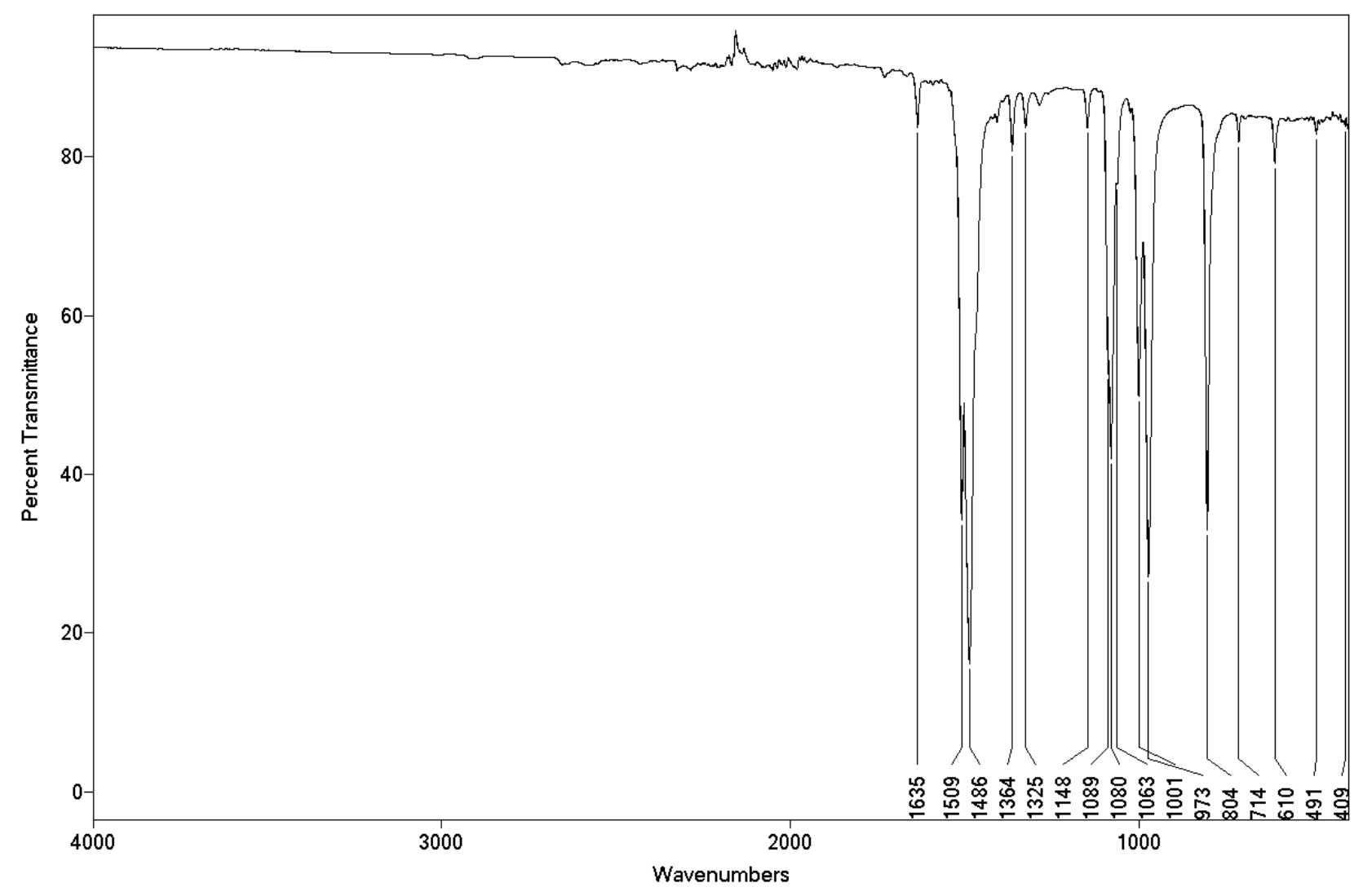

Figure S10. Pentafluoroiodobenzene (1e) ATR-FTIR spectrum.

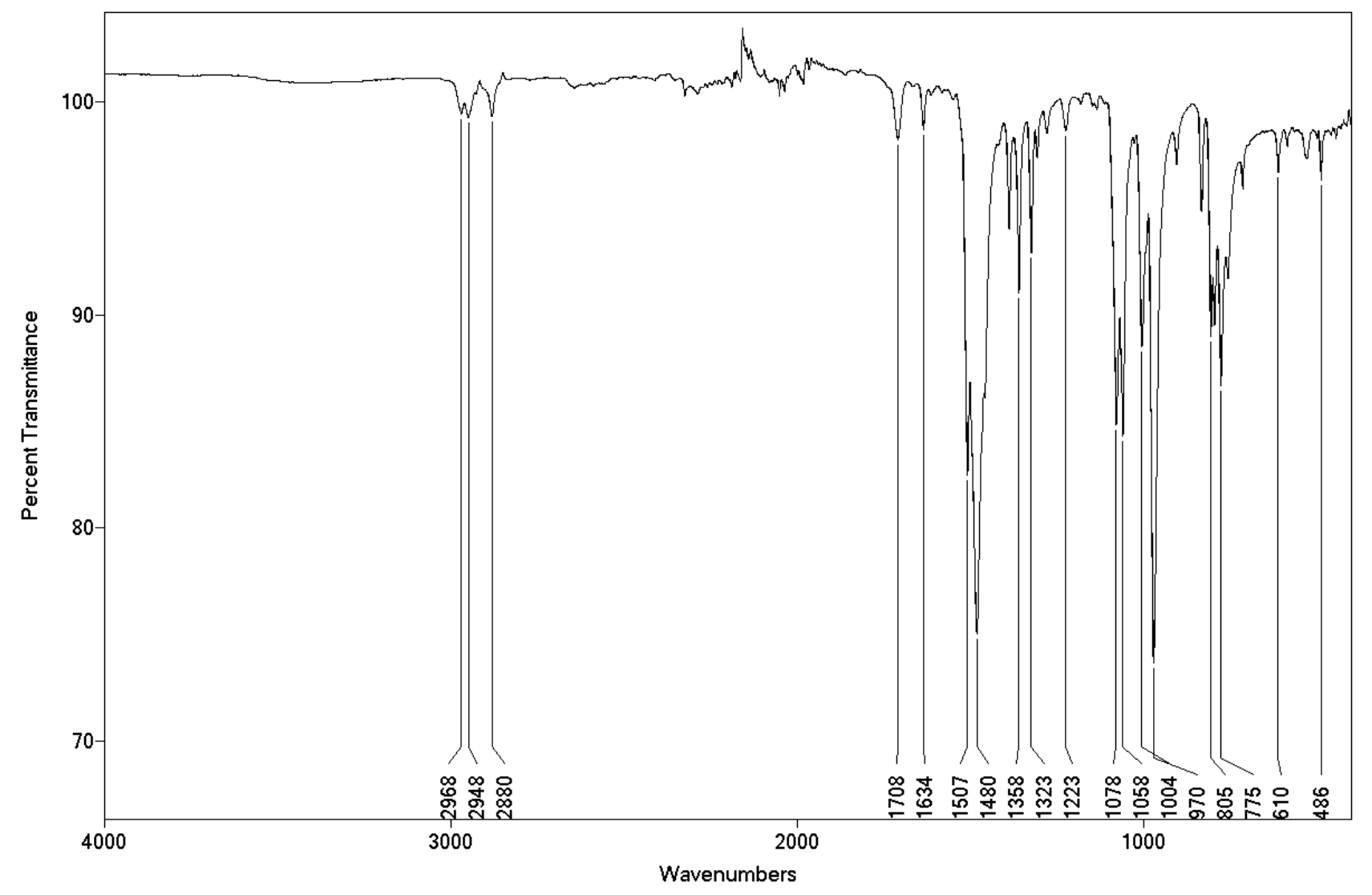

Figure S11. Co-crystal of 2e ATR-FTIR spectrum. 
Table S1. Co-crystals melting points.

Compounds $\quad \mathbf{M}_{\mathrm{p}}\left({ }^{\circ} \mathrm{C}\right)$

$2 a$

2b

$61-63$

2c

$71-72$

2d

$38-41$

$2 e$

104-105

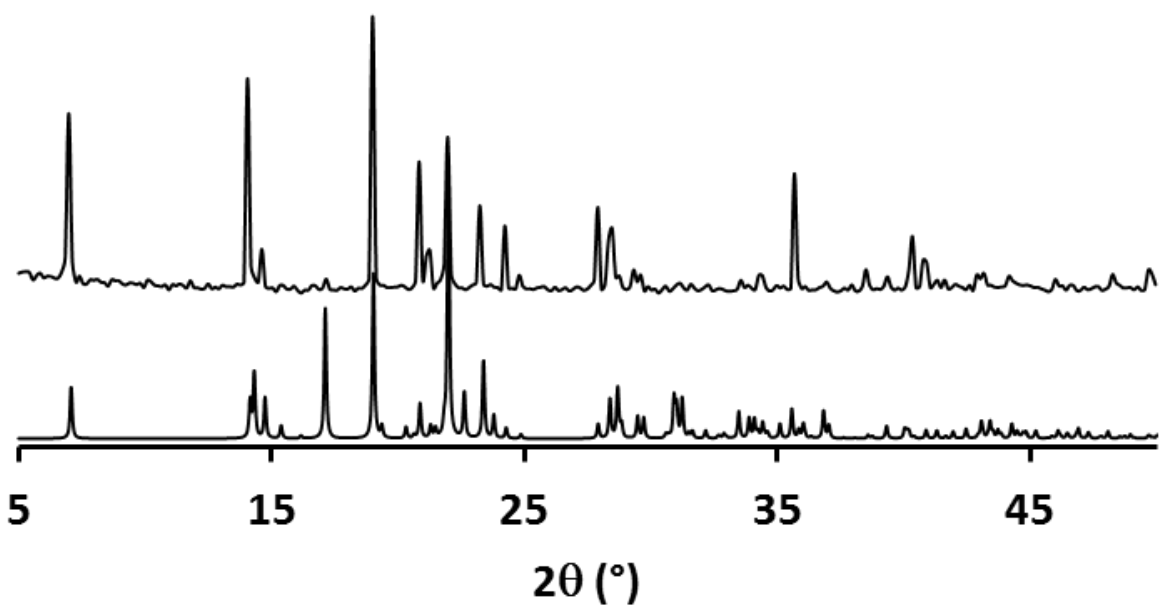

Figure S12. Comparison between calculated (bottom) and experimental (top) powder X-ray diffraction patterns of complex $\mathbf{2 a}$. 


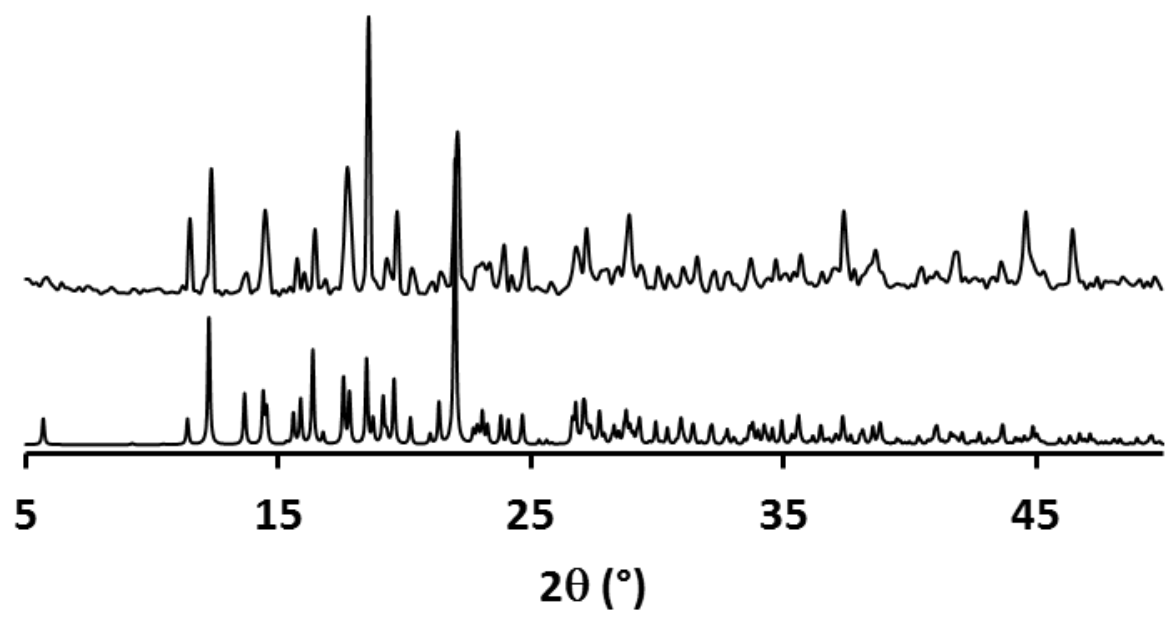

Figure S13. Comparison between calculated (bottom) and experimental (top) powder X-ray diffraction patterns of complex $\mathbf{2 b}$.

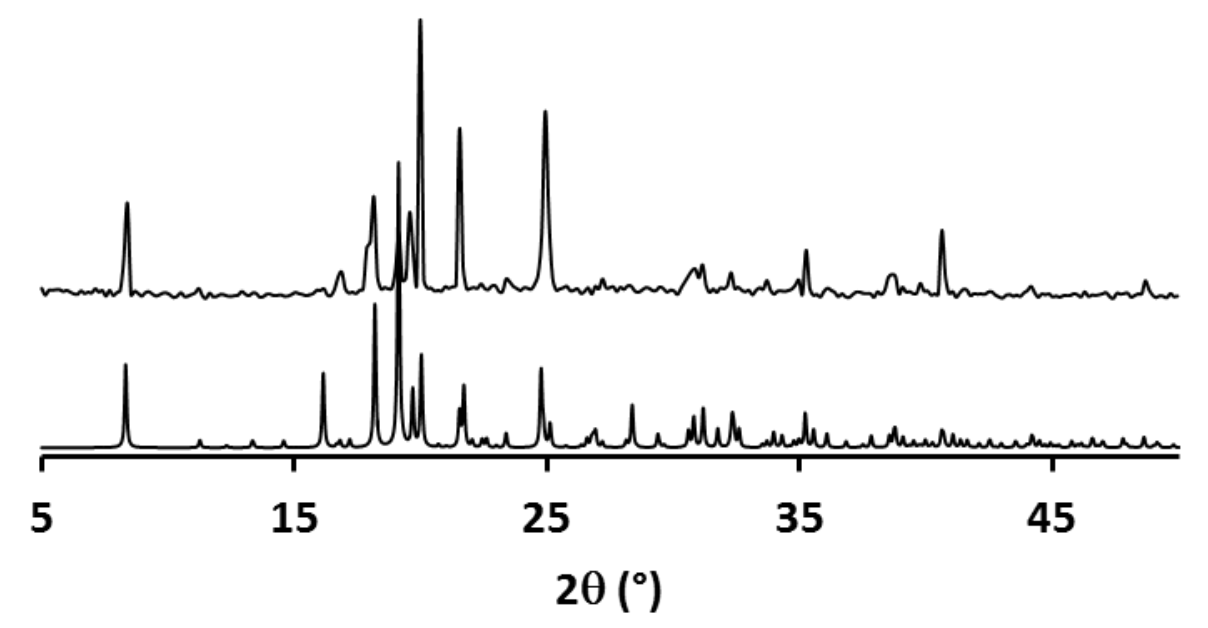

Figure S14. Comparison between calculated (bottom) and experimental (top) powder X-ray diffraction patterns of complex $\mathbf{2 c}$. 


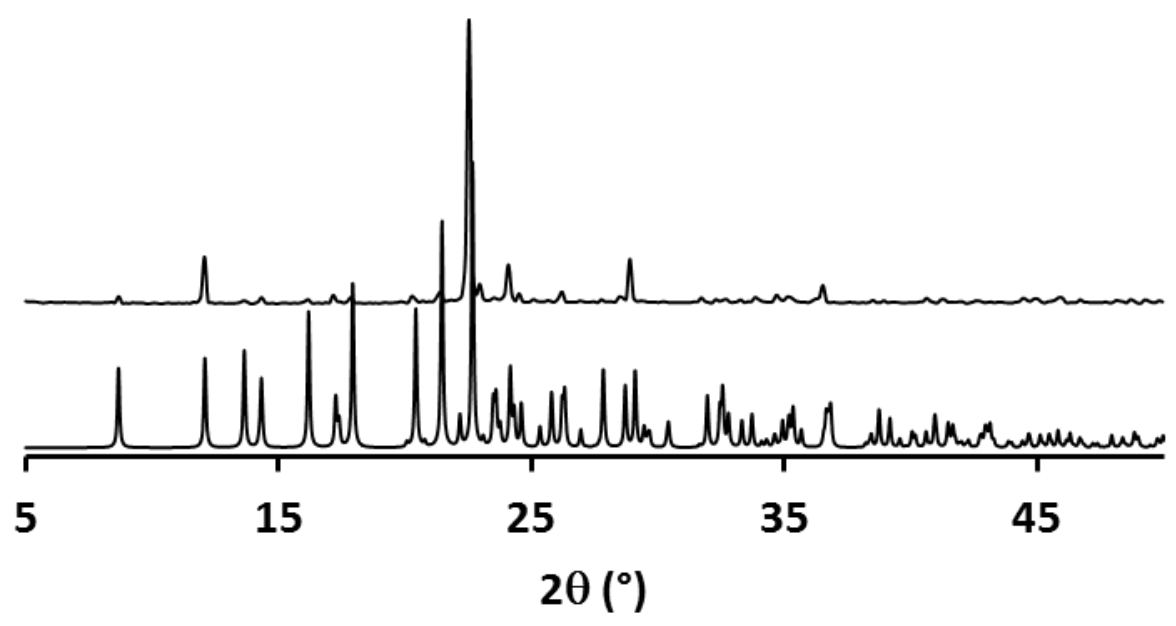

Figure S15. Comparison between calculated (bottom) and experimental (top) powder X-ray diffraction patterns of complex $\mathbf{2 d}$.

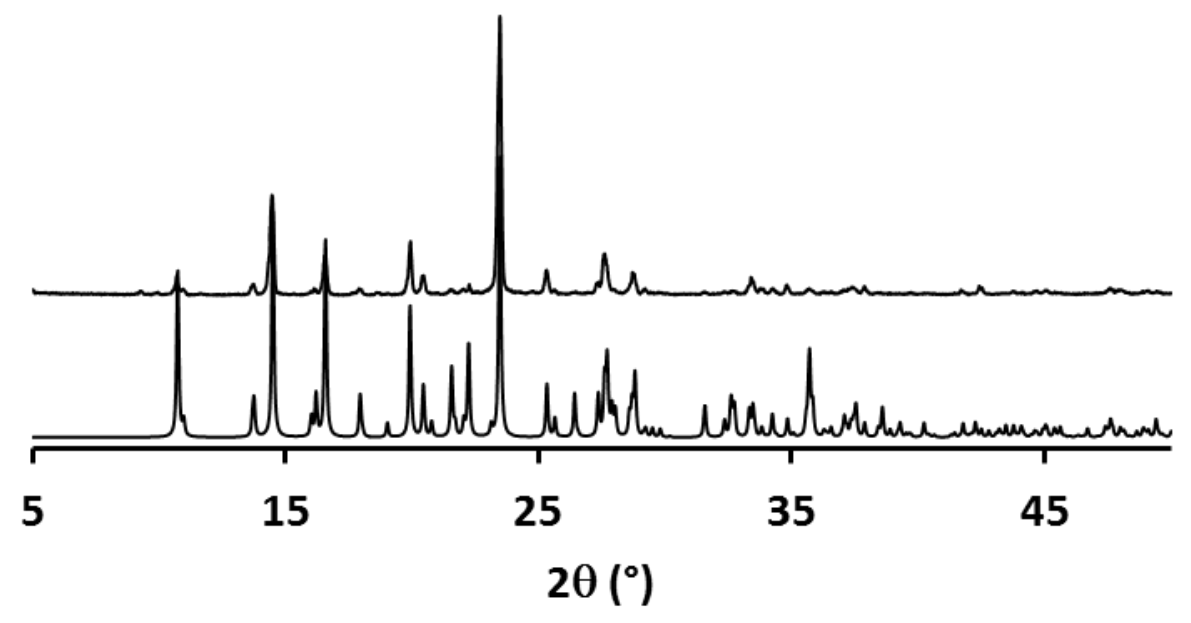

Figure S16. Comparison between calculated (bottom) and experimental (top) powder X-ray diffraction patterns of complex $\mathbf{2 e}$. 

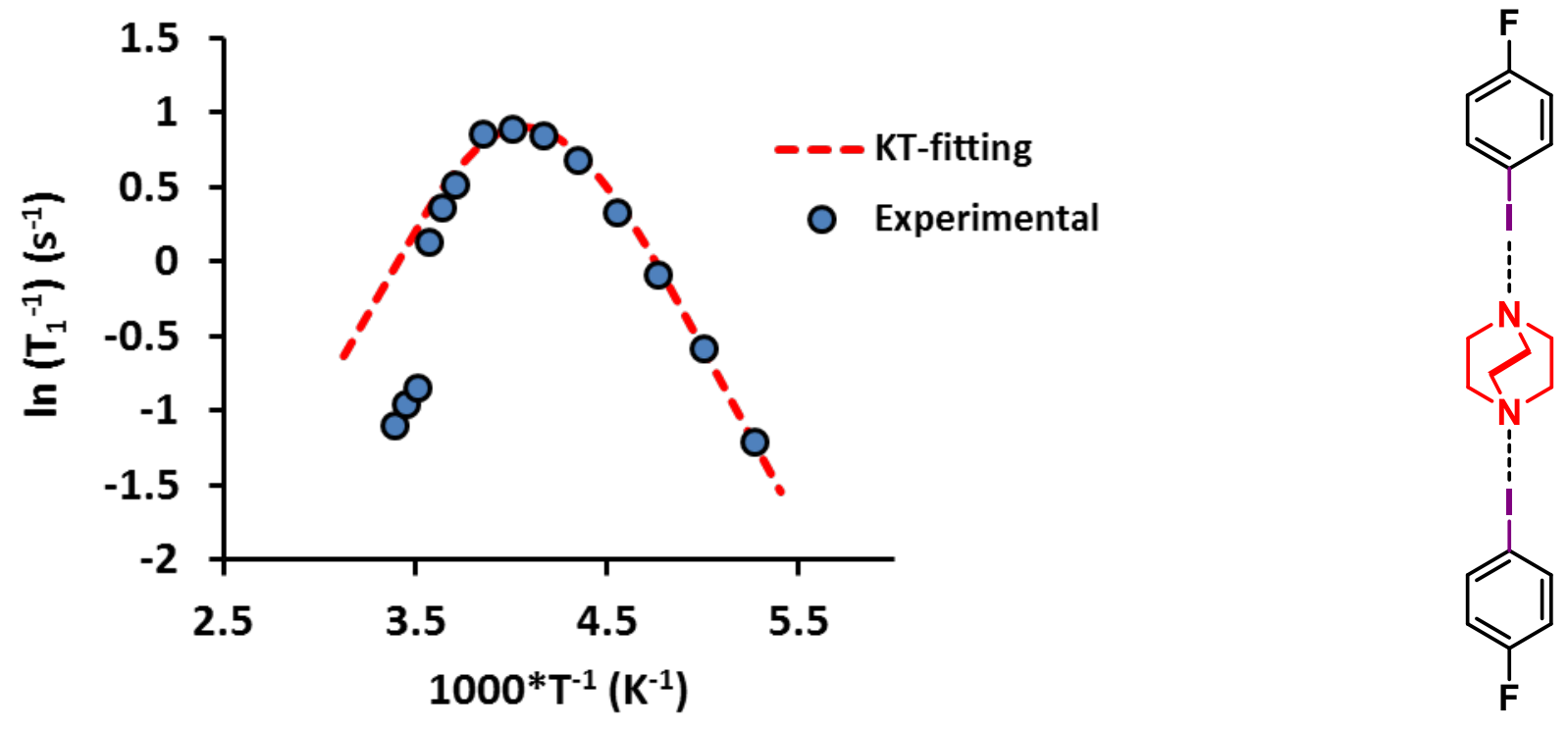

Figure S17. ${ }^{1} \mathrm{H}$ spin-lattice relaxation times $\left({ }^{1} \mathrm{H} \mathrm{T}_{1}\right)$ measured on 4-FPhI-dabco (2a) from $310 \mathrm{~K}-200$ $\mathrm{K}$ at $300 \mathrm{MHz}$ (solid blue circles). The plot $\ln \left(\mathrm{T}_{1}{ }^{-1}\right)$ vs $1000 \mathrm{~T}^{-1}$ shows two processes, one occurring close to room temperature and another at low temperature in the range of $280 \mathrm{~K}-200 \mathrm{~K}$. The low temperature process displays a maximum that corresponds to the minimum ${ }^{1} \mathrm{H} \mathrm{T}_{1}$, at approximately $250 \mathrm{~K}$. Assuming an Arrhenius behavior, the low temperature process was fitted to the Kubo-Tomita equation giving an $E_{a}=4.88 \mathrm{kcal} \cdot \mathrm{mol}^{-1}$ and $\tau_{0}^{-1}=9.9 \times 10^{12} \mathrm{~s}^{-1}$.
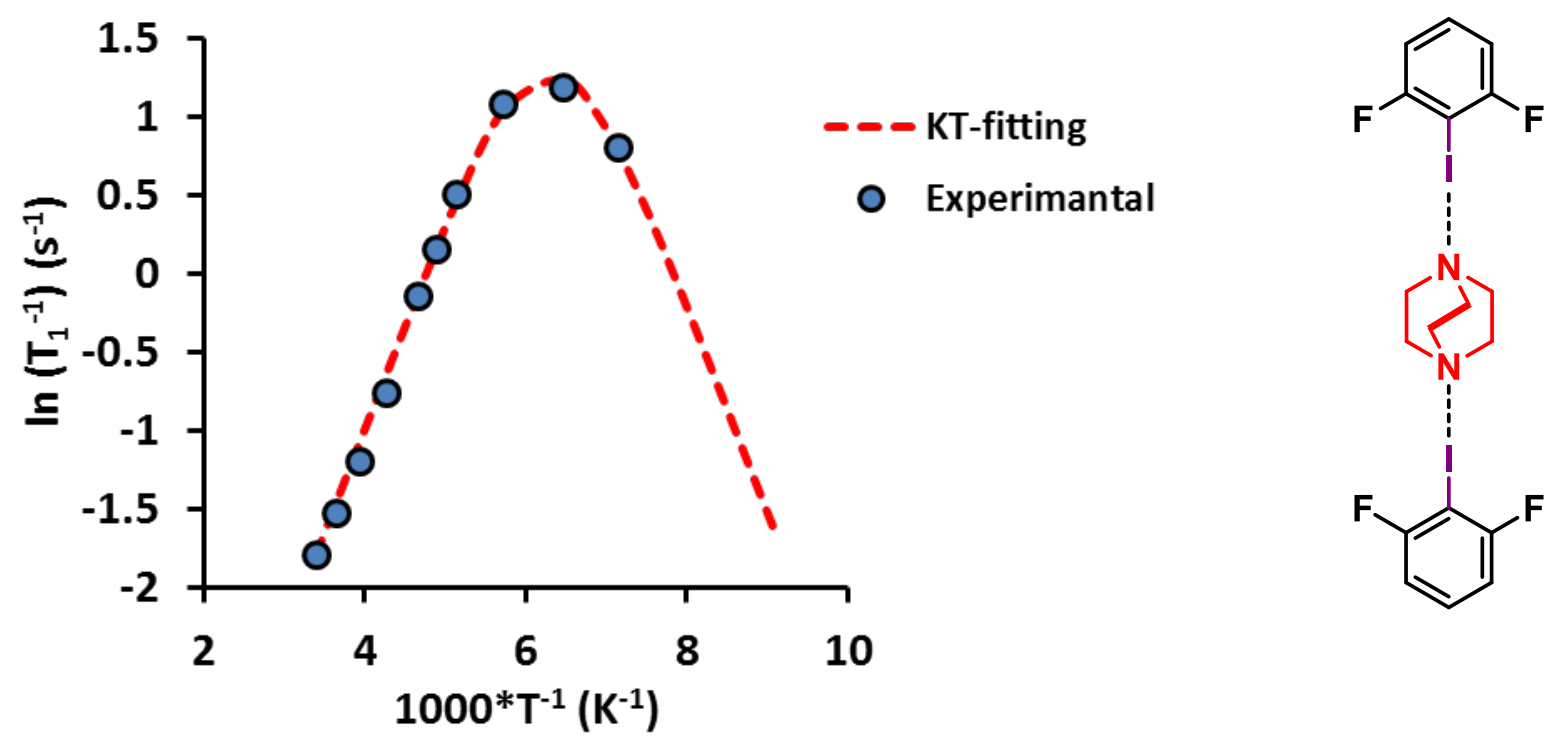

Figure S18. ${ }^{1} \mathrm{H}$ spin-lattice relaxation times $\left({ }^{1} \mathrm{H} \mathrm{T}_{1}\right)$ measured on 2,6- $\mathrm{F}_{2} \mathrm{PhI} \cdot$ dabco $(\mathbf{2 b})$ from $295 \mathrm{~K}$ $-145 \mathrm{~K}$ at $300 \mathrm{MHz}$ (solid blue circles). The plot $\ln \left(\mathrm{T}_{1}^{-1}\right)$ vs $1000 \mathrm{~T}^{-1}$ shows a strong dependence of ${ }^{1} \mathrm{H} \mathrm{T}_{1}$ with the temperature displaying a maximum, that corresponds to the minimum ${ }^{1} \mathrm{H} \mathrm{T}_{1}$, at approximately $155 \mathrm{~K}$. The red dotted line corresponds to the Kubo-Tomita fit for the process assuming an Arrhenius behavior with an $E_{a}=2.65 \mathrm{kcal} \cdot \mathrm{mol}^{-1}$ and $\tau_{0}^{-1}=2.0 \times 10^{12} \mathrm{~s}^{-1}$. 

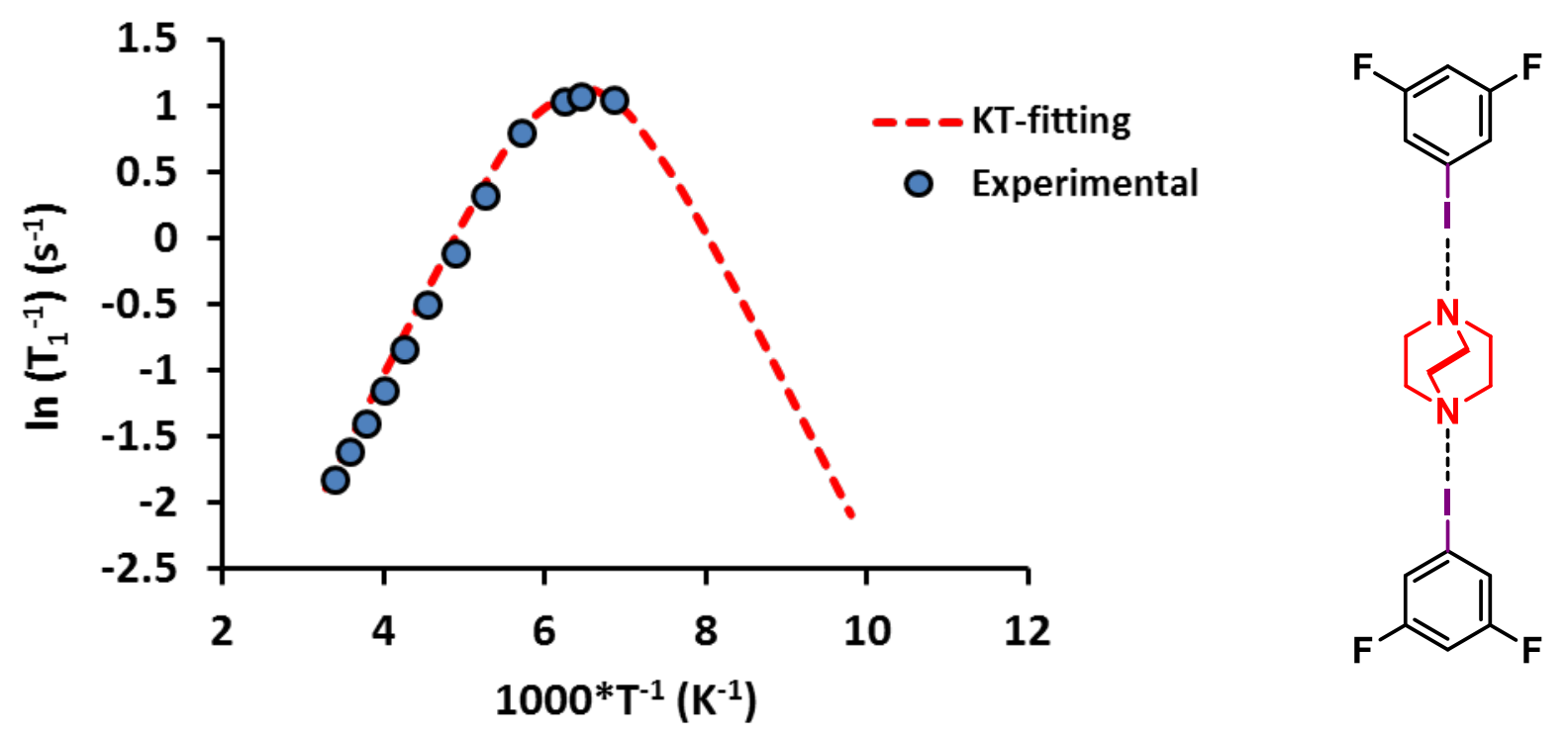

Figure S19. ${ }^{1} \mathrm{H}$ spin-lattice relaxation times $\left({ }^{1} \mathrm{H} \mathrm{T}_{1}\right)$ measured on 3,5- $\mathrm{F}_{2} \mathrm{PhI} \cdot \mathrm{dabco}(\mathbf{2 c})$ from $196 \mathrm{~K}$ - $146 \mathrm{~K}$ at $300 \mathrm{MHz}$. The plot $\ln \left(\mathrm{T}_{1}^{-1}\right)$ vs $1000 \mathrm{~T}^{-1}$ shows a maximum, that corresponds to the minimum ${ }^{1} \mathrm{H} \mathrm{T}_{1}$, at approximately $155 \mathrm{~K}$. The red dotted line corresponds to the Kubo-Tomita fit for the process assuming an Arrhenius behavior with an $E_{a}=2.4 \mathrm{kcal} \cdot \mathrm{mol}^{-1}$ and $\tau_{0}^{-1}=1.1 \times 10^{12} \mathrm{~s}^{-1}$
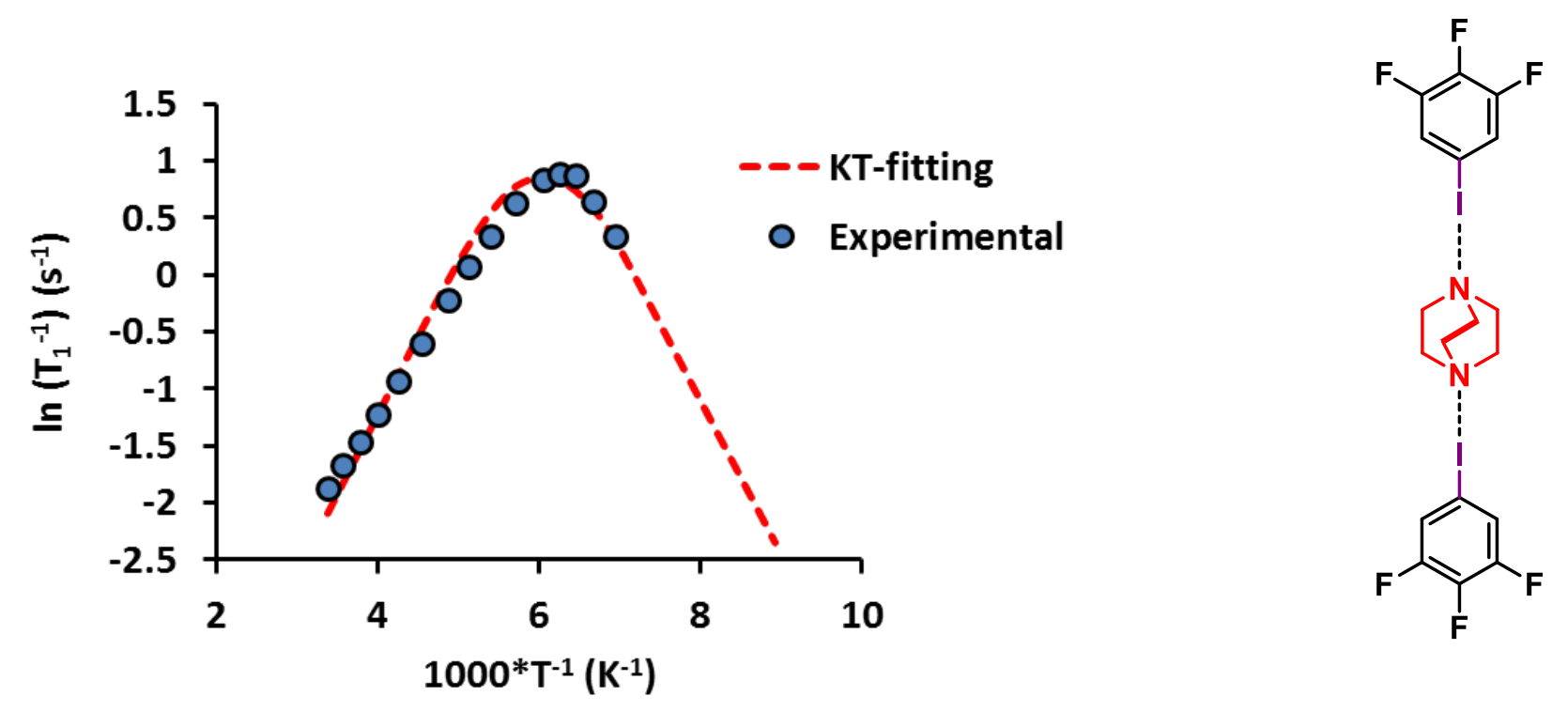

Figure S20. ${ }^{1} \mathrm{H}$ spin-lattice relaxation times $\left({ }^{1} \mathrm{H} \mathrm{T}_{1}\right)$ measured on 3,4,5-F $\mathrm{F}_{3} \mathrm{PhI} \cdot$ dabco $(\mathbf{2 d})$ from 296 $\mathrm{K}-150 \mathrm{~K}$ at $300 \mathrm{MHz}$ (solid blue circles). The plot $\ln \left(\mathrm{T}_{1}^{-1}\right)$ vs $1000 \mathrm{~T}^{-1}$ shows a strong dependence of ${ }^{1} \mathrm{H} \mathrm{T}_{1}$ with the temperature displaying a maximum, that corresponds to the minimum ${ }^{1} \mathrm{H} \mathrm{T}_{1}$, at approximately $160 \mathrm{~K}$. The red dotted line corresponds to the Kubo-Tomita fit for the process assuming an Arrhenius behavior with an $E_{a}=2.8 \mathrm{kcal} \cdot \mathrm{mol}^{-1}$ and $\tau_{0}^{-1}=2.3 \times 10^{12} \mathrm{~s}^{-1}$. 


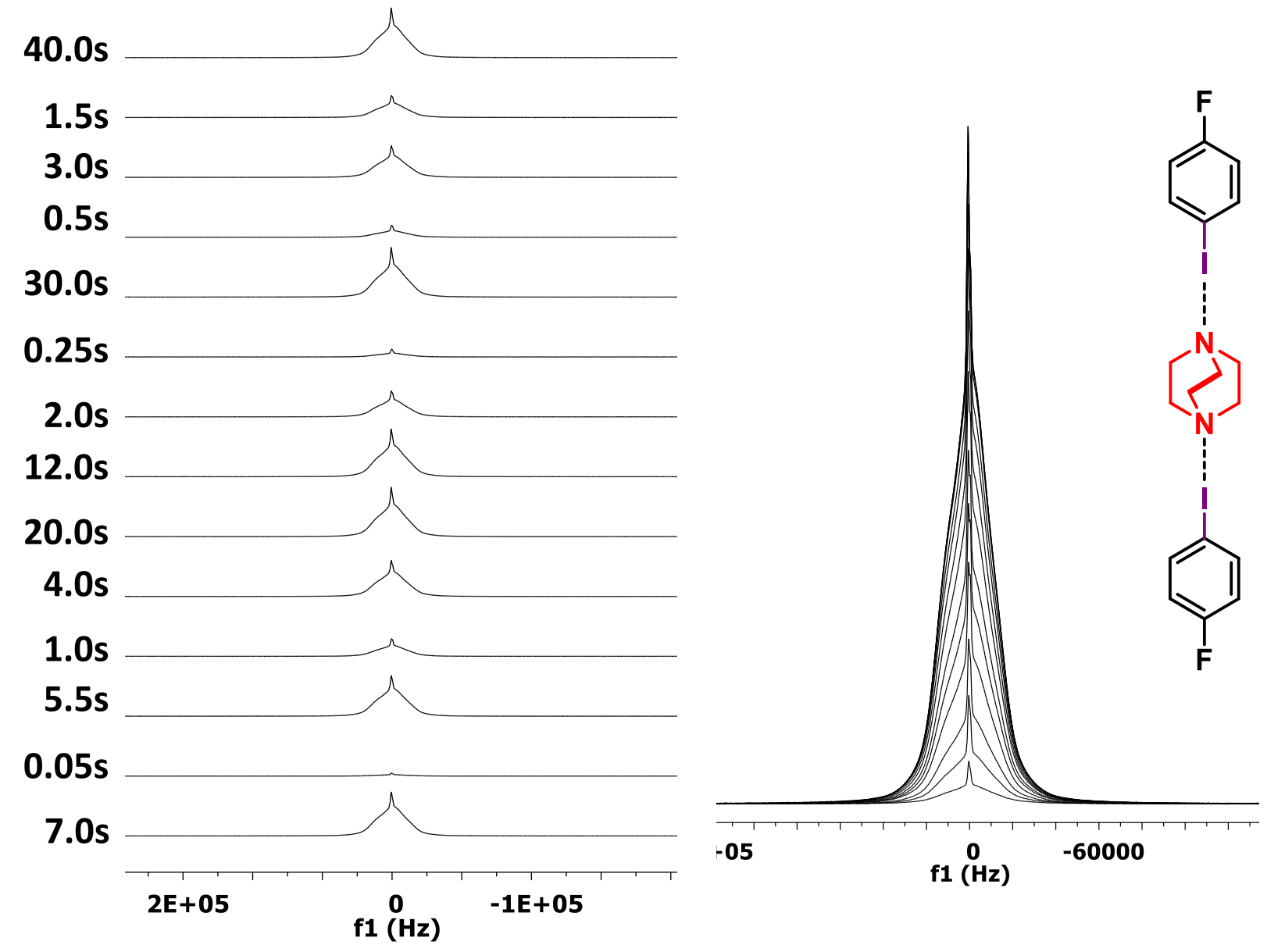

Figure S21. Representative ${ }^{1} \mathrm{H}$ wideline spin-lattice relaxtion $\left(\mathrm{T}_{1}\right)$ NMR measurement via the saturation-recovery method at $290 \mathrm{~K}$ : stacked spectra (left) and overlaid spectra (right). 


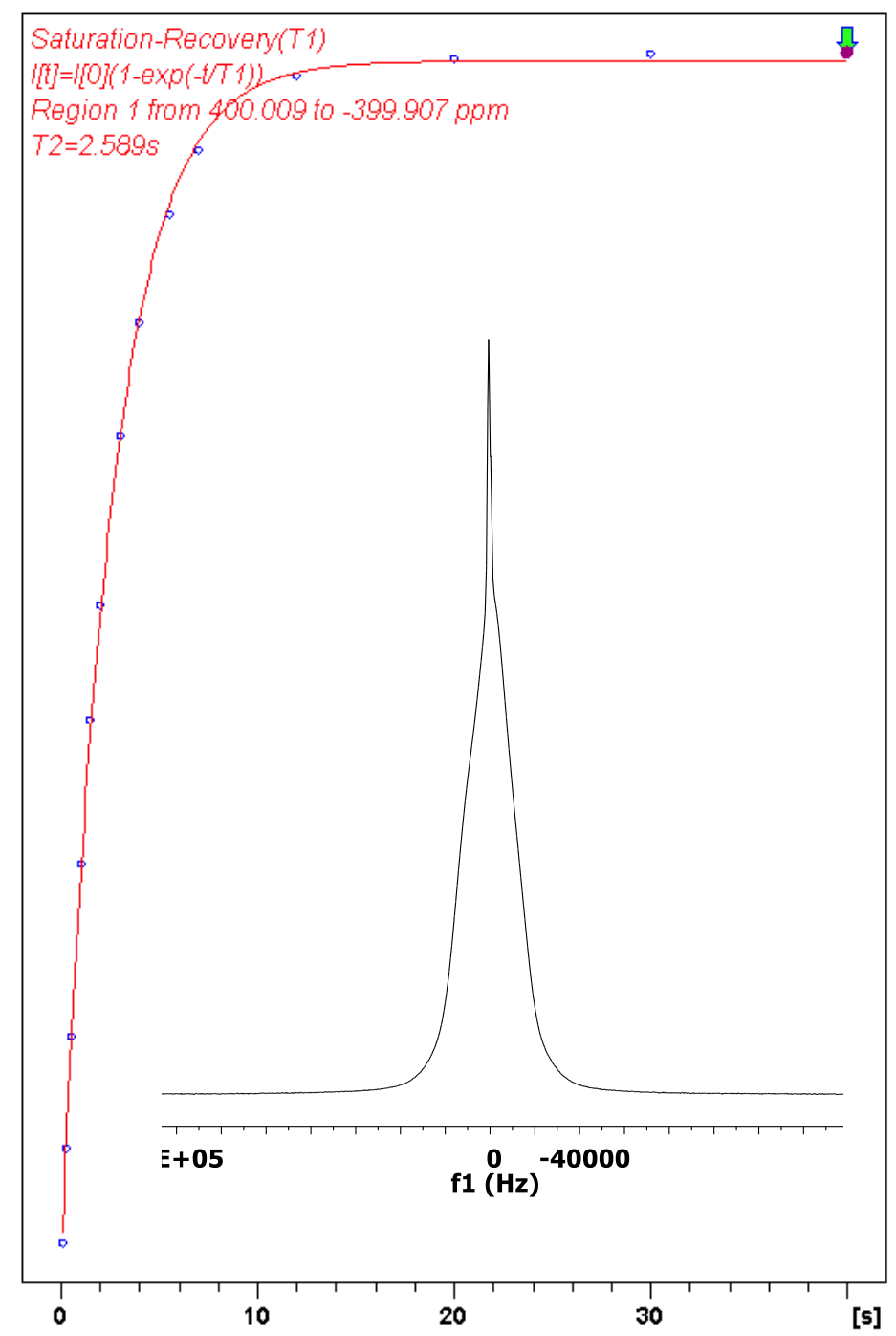

Figure S22. Representative example of the mono-exponential fit to representative ${ }^{1} \mathrm{H}$ wideline spinlattice relaxation $\left(\mathrm{T}_{1}\right)$ saturation recovery data of complex $2 \mathrm{a}$ at $\mathrm{T}=290 \mathrm{~K}\left(\mathrm{~T}_{1}=2.589 \mathrm{~s}\right)$ with $\tau$ ' values of $7 \mathrm{~s}, 0.05 \mathrm{~s}, 5.5 \mathrm{~s}, 1 \mathrm{~s}, 4 \mathrm{~s}, 20 \mathrm{~s}, 12 \mathrm{~s}, 2 \mathrm{~s}, 0.25 \mathrm{~s}, 30 \mathrm{~s}, 0.5 \mathrm{~s}, 3 \mathrm{~s}, 1.5 \mathrm{~s}, 40 \mathrm{~s}$. The insert shows the recovery of the signal at $40 \mathrm{~s}$. 

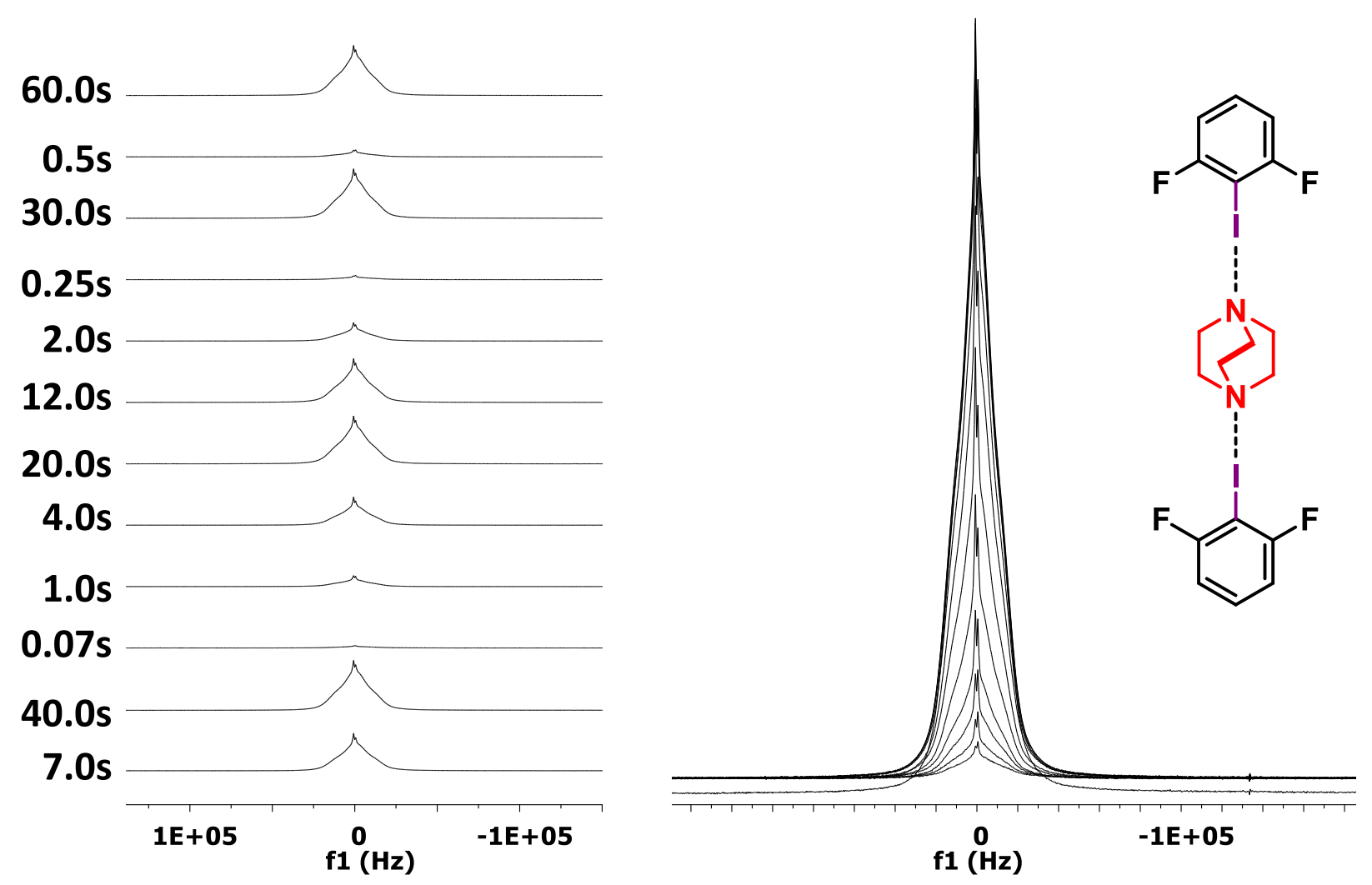

Figure S23. Representative ${ }^{1} \mathrm{H}$ wideline spin-lattice relaxtion $\left(\mathrm{T}_{1}\right)$ NMR measurement via the saturation-recovery method at $295 \mathrm{~K}$ : stacked spectra (left) and overlaid spectra (right). 

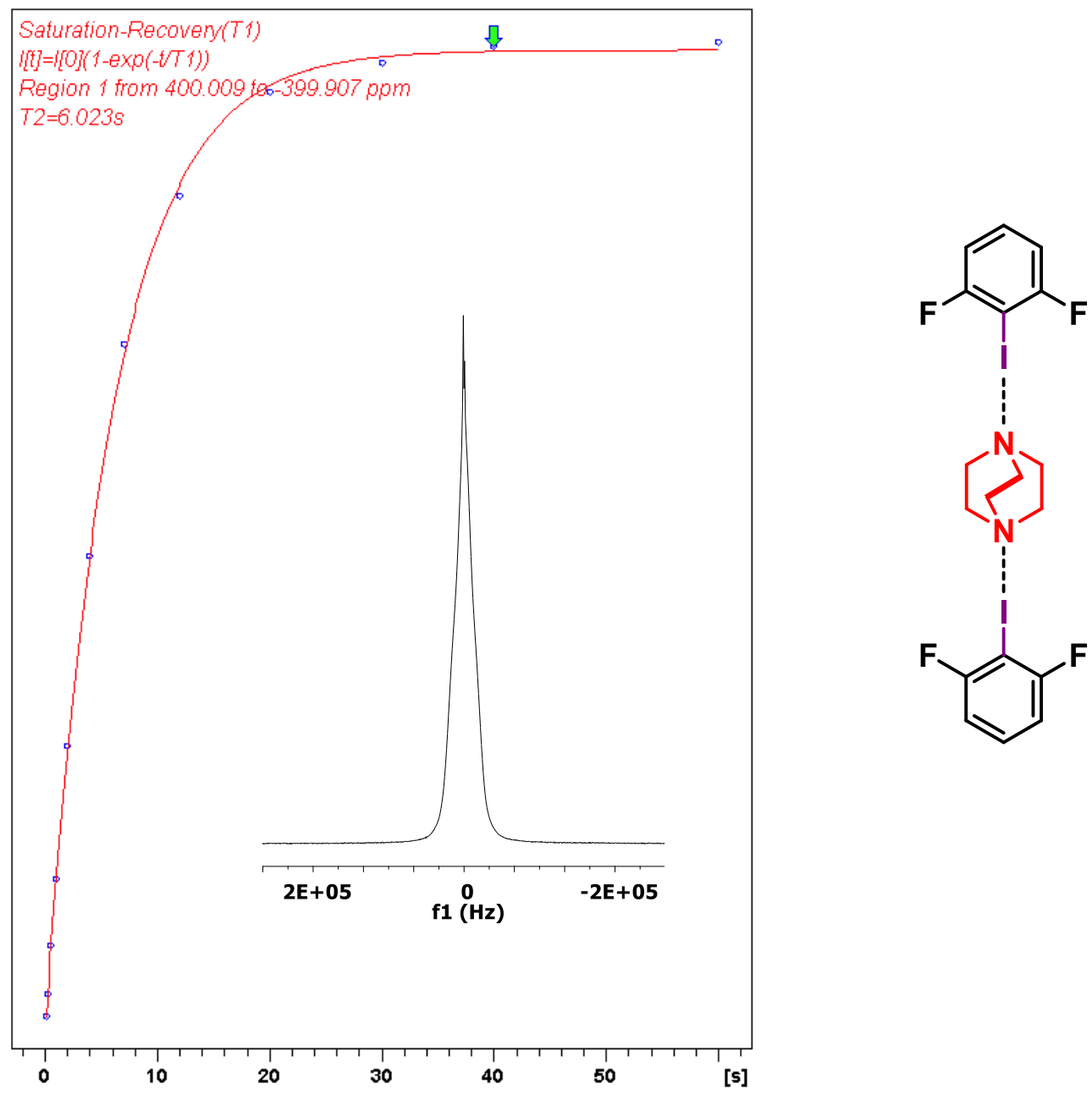

Figure S24. Representative example of the mono-exponential fit to representative ${ }^{1} \mathrm{H}$ wideline spinlattice relaxation $\left(\mathrm{T}_{1}\right)$ saturation recovery data of complex $2 \mathrm{~b}$ at $\mathrm{T}=295 \mathrm{~K}\left(\mathrm{~T}_{1}=6.0 \mathrm{~s}\right)$ with $\tau$ ' values of $7 \mathrm{~s}, 40 \mathrm{~s}, 0.07 \mathrm{~s}, 1 \mathrm{~s}, 4 \mathrm{~s}, 20 \mathrm{~s}, 12 \mathrm{~s}, 2 \mathrm{~s}, 0.25 \mathrm{~s}, 30 \mathrm{~s}, 0.5 \mathrm{~s}, 60 \mathrm{~s}$. The insert shows the recovery of the signal at $60 \mathrm{~s}$. 

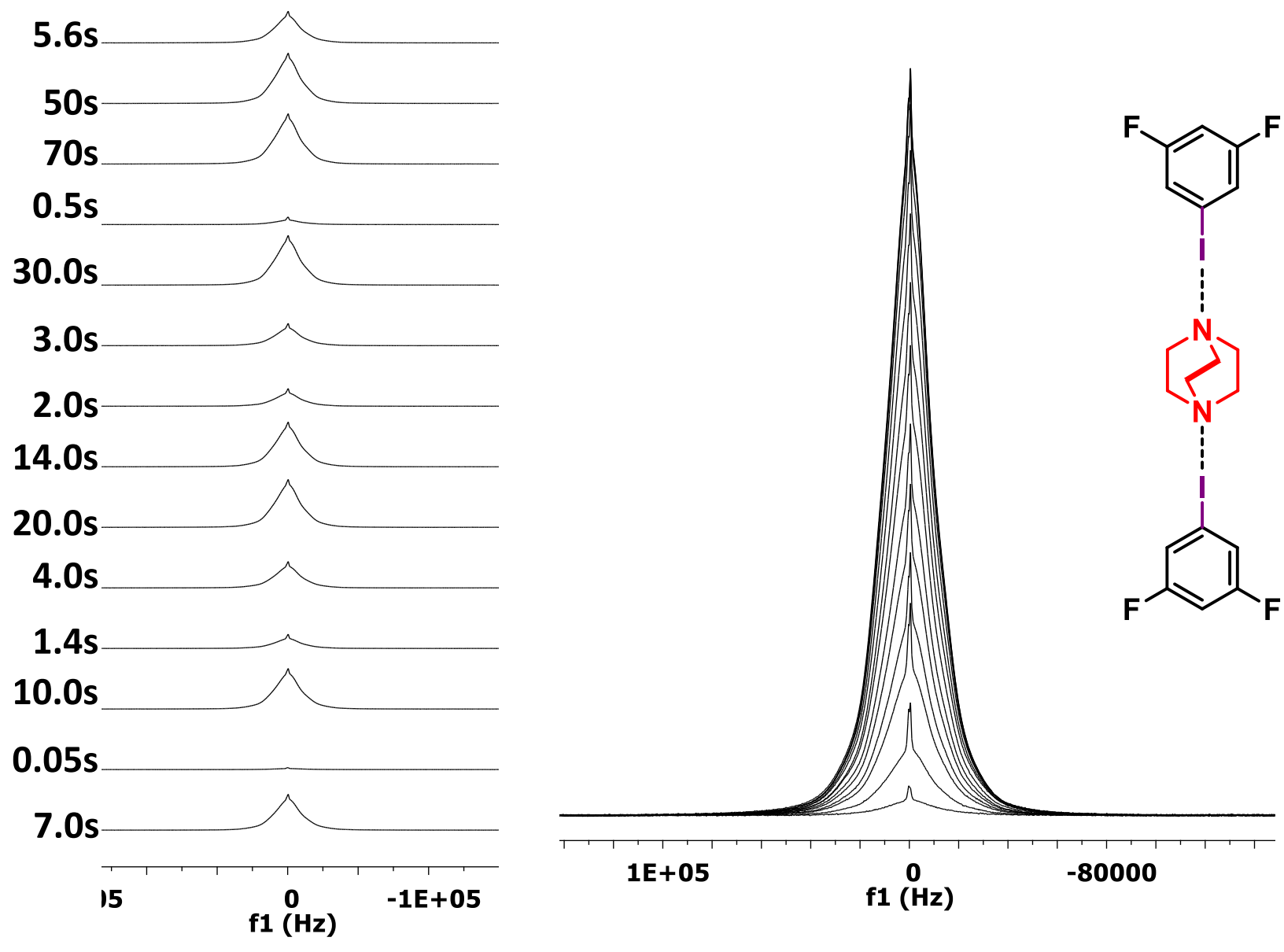

Figure S25. Representative ${ }^{1} \mathrm{H}$ wideline spin-lattice relaxtion $\left(\mathrm{T}_{1}\right)$ NMR measurement via the saturation-recovery method at $296 \mathrm{~K}$ : stacked spectra (left) and overlaid spectra (right). 


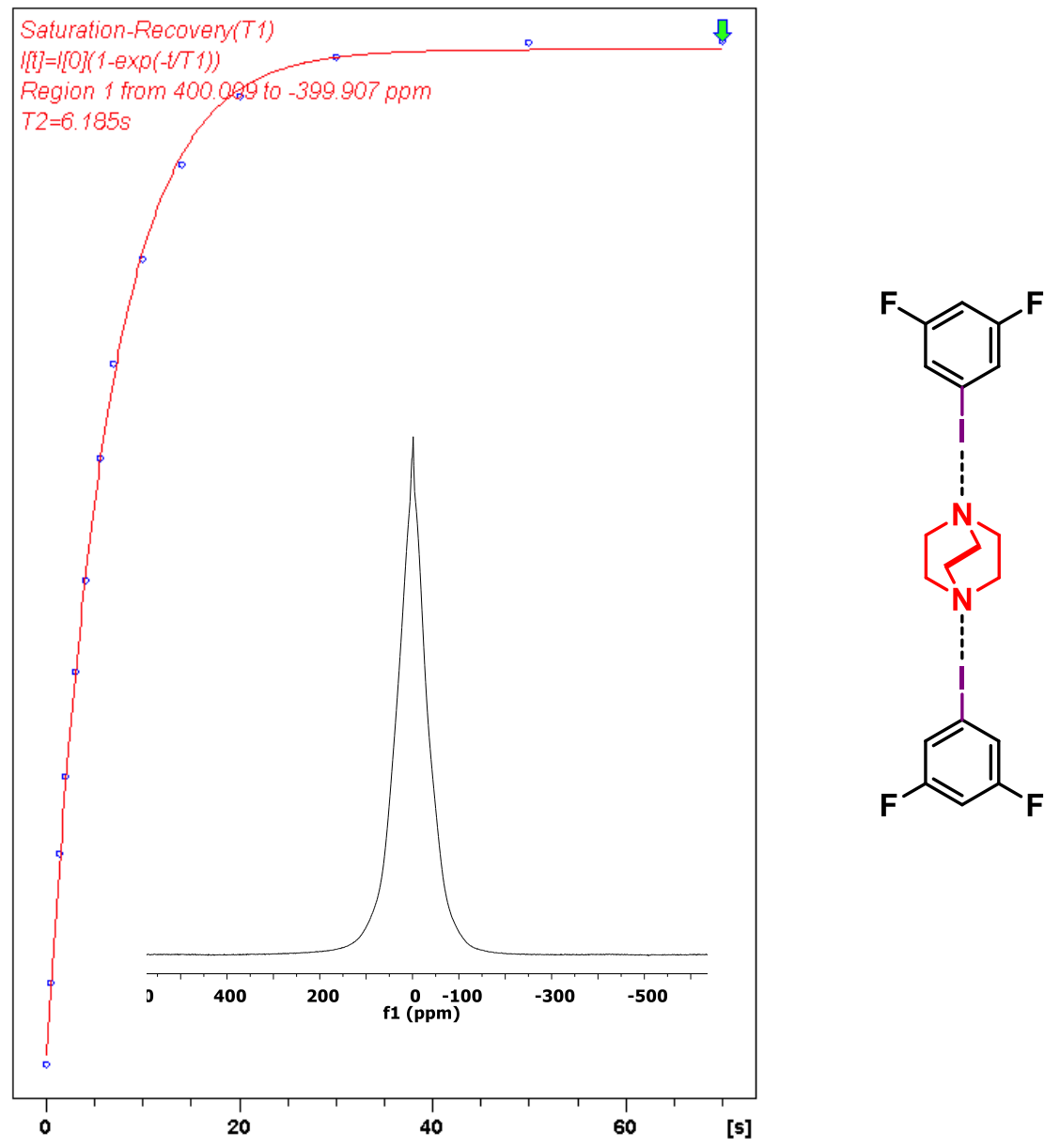

Figure S26. Representative example of the mono-exponential fit to representative ${ }^{1} \mathrm{H}$ wideline spinlattice relaxation $\left(\mathrm{T}_{1}\right)$ saturation recovery data of complex $2 \mathrm{c}$ at $\mathrm{T}=296 \mathrm{~K}\left(\mathrm{~T}_{1}=6.185 \mathrm{~s}\right)$ with $\tau$ ' values of $7 \mathrm{~s}, 0.05 \mathrm{~s}, 10 \mathrm{~s}, 1.4 \mathrm{~s}, 4 \mathrm{~s}, 20 \mathrm{~s}, 14 \mathrm{~s}, 2 \mathrm{~s}, 3 \mathrm{~s}, 30 \mathrm{~s}, 0.5 \mathrm{~s}, 70 \mathrm{~s}, 50 \mathrm{~s}, 5.6 \mathrm{~s}$. The insert shows the recovery of the signal at $70 \mathrm{~s}$. 

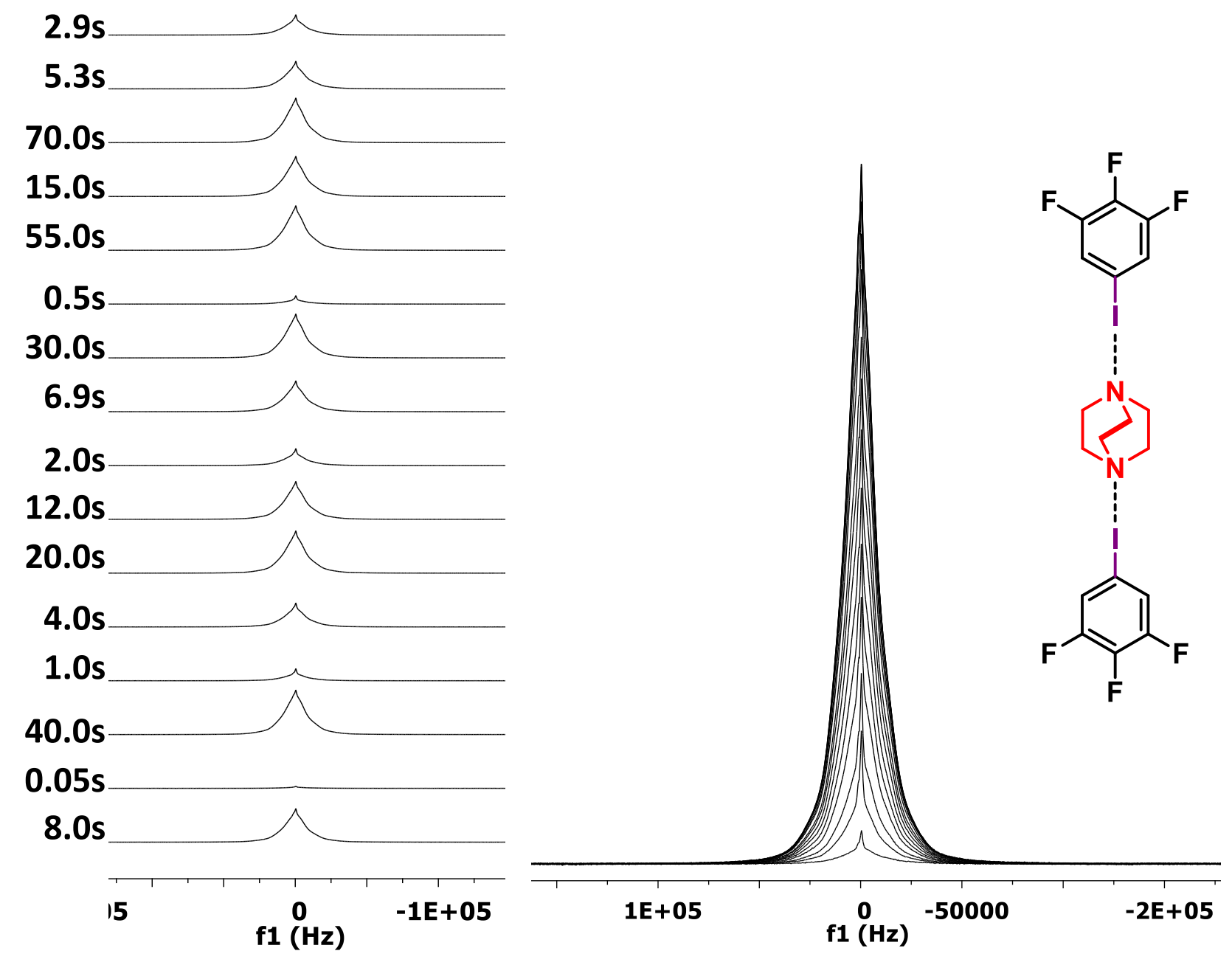

Figure S27. Representative ${ }^{1} \mathrm{H}$ wideline spin-lattice relaxtion $\left(\mathrm{T}_{1}\right)$ NMR measurement via the saturation-recovery method at $295 \mathrm{~K}$ : stacked spectra (left) and overlaid spectra (right). 

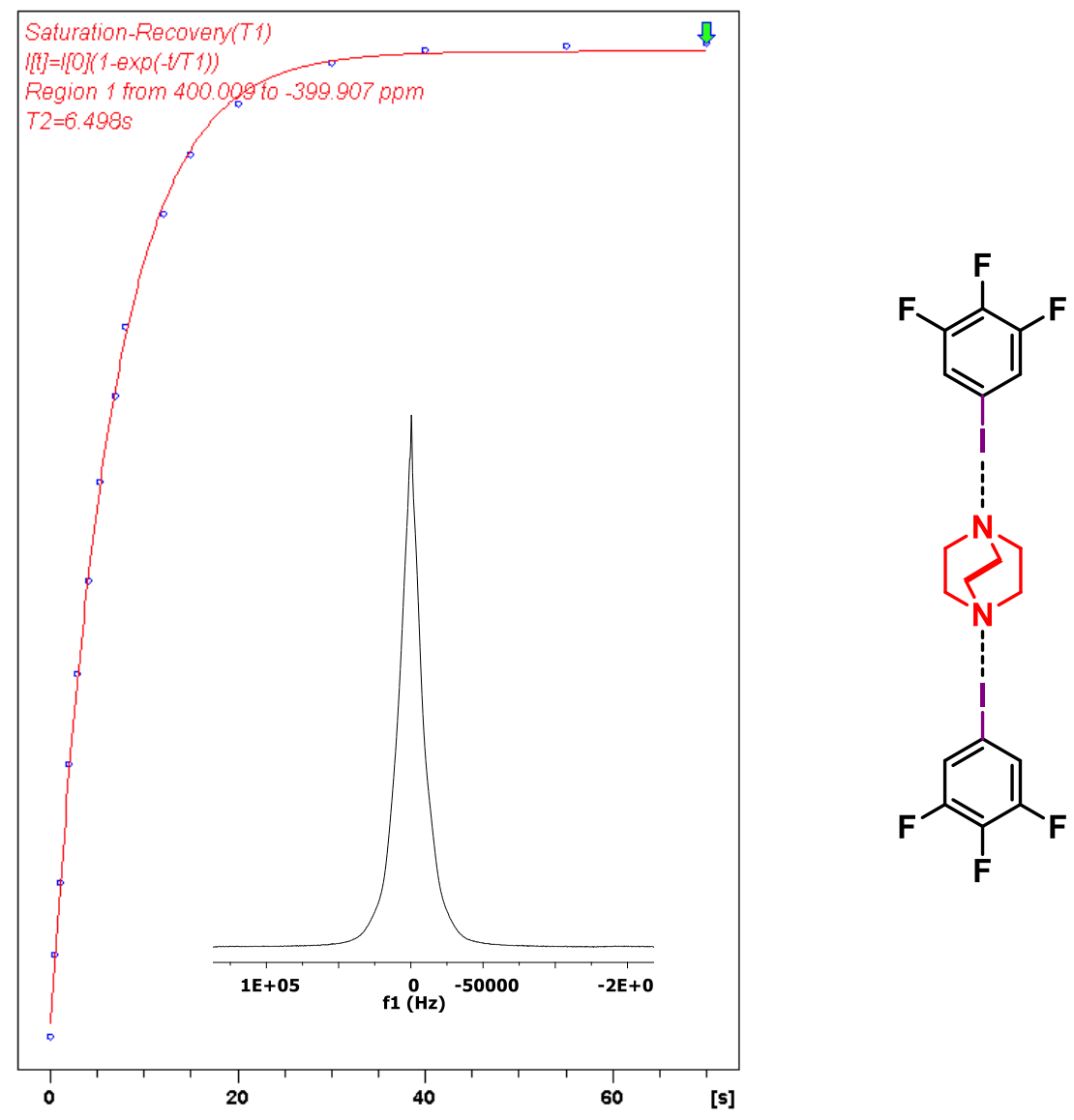

Figure S28. Representative example of the mono-exponential fit to representative ${ }^{1} \mathrm{H}$ wideline spinlattice relaxation $\left(\mathrm{T}_{1}\right)$ saturation recovery data of complex $2 \mathrm{~d}$ at $\mathrm{T}=296 \mathrm{~K}\left(\mathrm{~T}_{1}=6.498 \mathrm{~s}\right)$ with $\tau$ ' values of $8 \mathrm{~s}, 0.05 \mathrm{~s}, 40 \mathrm{~s}, 1 \mathrm{~s}, 4 \mathrm{~s}, 20 \mathrm{~s}, 12 \mathrm{~s}, 2 \mathrm{~s}, 6.9 \mathrm{~s}, 30 \mathrm{~s}, 0.5 \mathrm{~s}, 55 \mathrm{~s}, 15 \mathrm{~s}, 70 \mathrm{~s}, 5.3 \mathrm{~s}, 2.9 \mathrm{~s}$. The insert shows the recovery of the signal at $70 \mathrm{~s}$. 


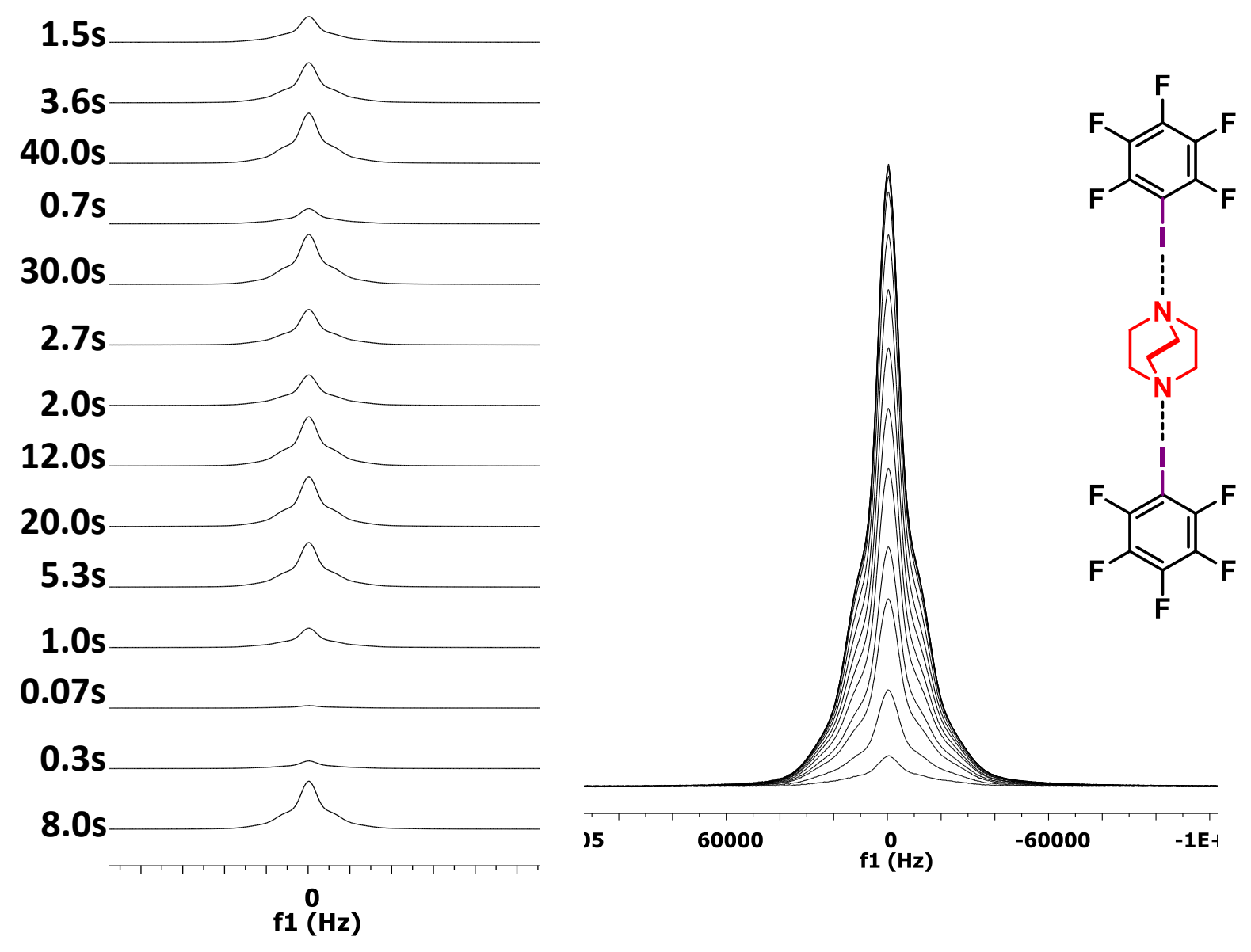

Figure S29. Representative ${ }^{1} \mathrm{H}$ wideline spin-lattice relaxtion $\left(\mathrm{T}_{1}\right)$ NMR measurement via the saturation-recovery method at $275 \mathrm{~K}$ : stacked spectra (left) and overlaid spectra (right). 


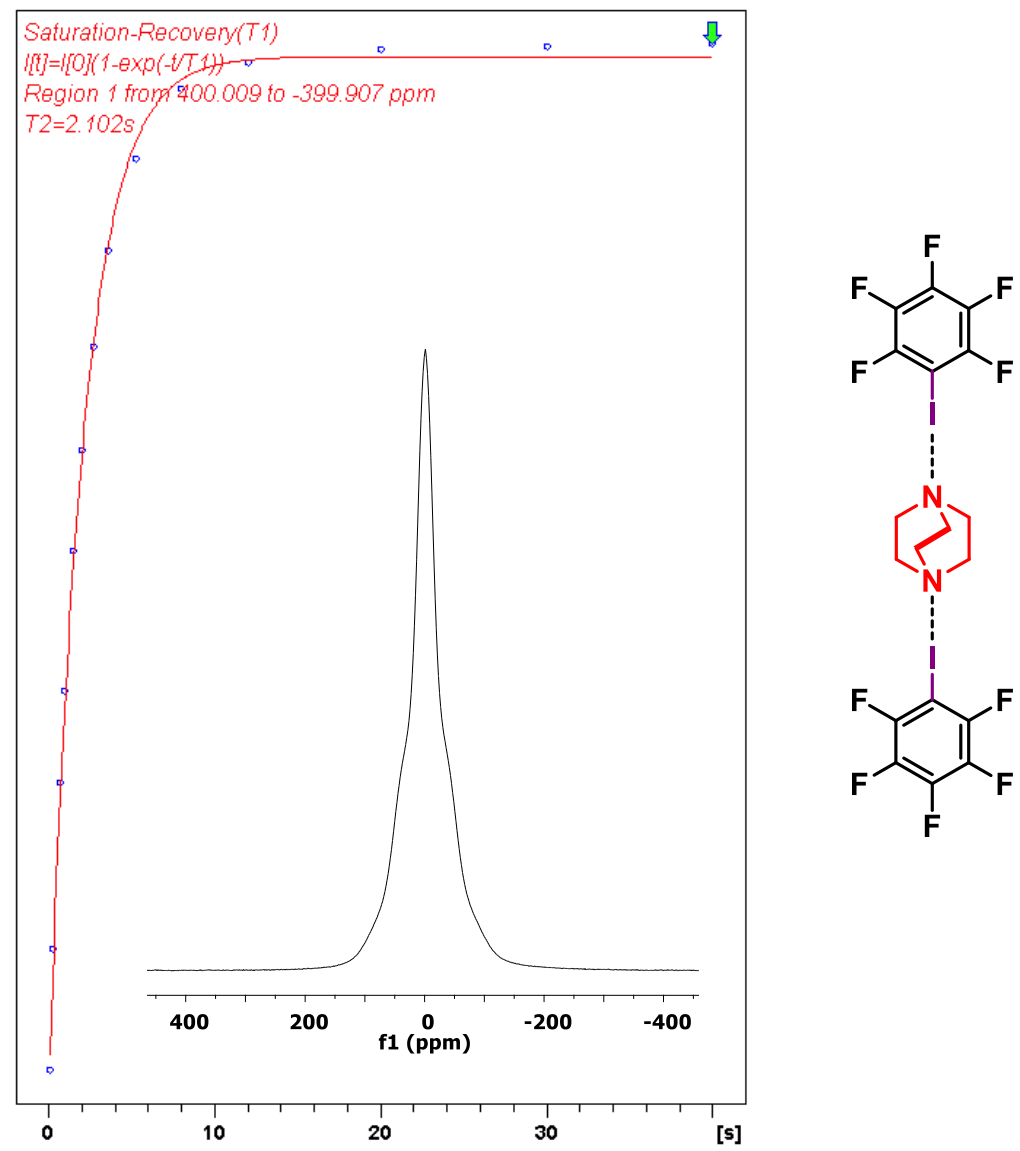

Figure S30. Representative example of the mono-exponential fit to representative ${ }^{1} \mathrm{H}$ wideline spinlattice relaxation $\left(\mathrm{T}_{1}\right)$ saturation recovery data of complex $2 \mathrm{e}$ at $\mathrm{T}=275 \mathrm{~K}\left(\mathrm{~T}_{1}=2.102 \mathrm{~s}\right)$ with $\tau$ ' values of $8 \mathrm{~s}, 0.3 \mathrm{~s}, 0.07 \mathrm{~s}, 1 \mathrm{~s}, 5.3 \mathrm{~s}, 20 \mathrm{~s}, 12 \mathrm{~s}, 2 \mathrm{~s}, 2.7 \mathrm{~s}, 30 \mathrm{~s}, 0.7 \mathrm{~s}, 40 \mathrm{~s}, 3.6 \mathrm{~s}, 1.5 \mathrm{~s}$. The insert shows the recovery of the signal at $40 \mathrm{~s}$. 


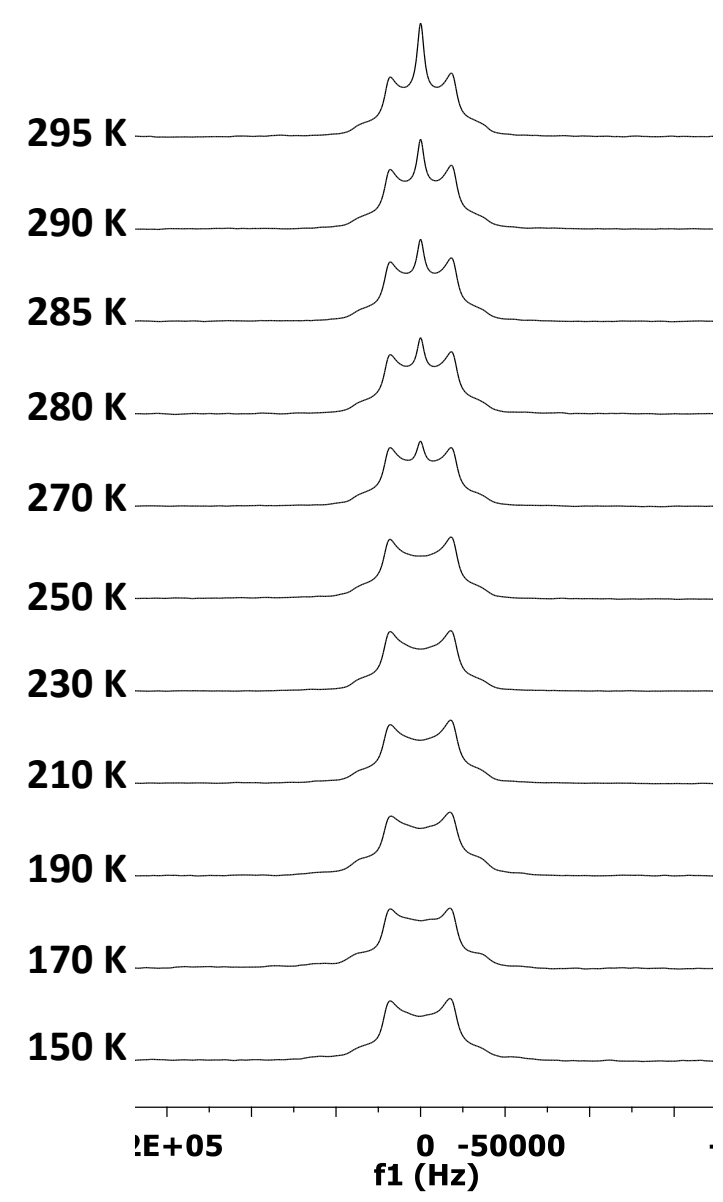

Figure s31. Variable temperature ${ }^{2} \mathrm{H}$ NMR quadrupolar echo experiments for complex FPhI-DABCO- $d_{12}\left(\mathbf{2 a -} \boldsymbol{d}_{12}\right)$ from $295 \mathrm{~K}$ to $150 \mathrm{~K}$.
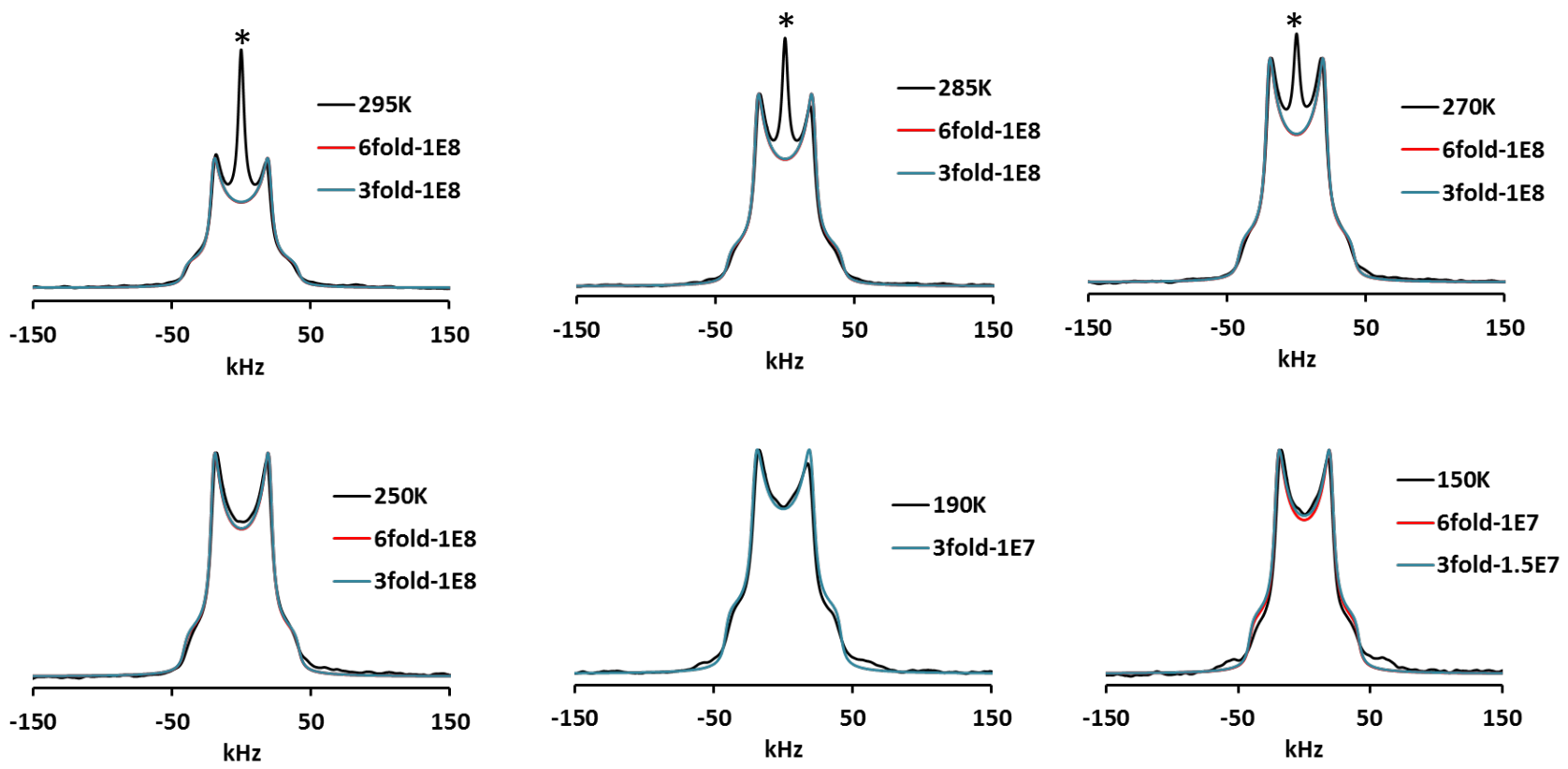

Figure S32. Experimental and simulated ${ }^{2} \mathrm{H}$ NMR quadrupolar echo spectra of $\mathbf{2 a -} \boldsymbol{d}_{\mathbf{1 2}}$. Simulations were carried out using the Nishikiori's program with a $\beta$ angle of $70^{\circ}$, a QCC of $170 \mathrm{kHz}$, a line- 
broadening of $5 \mathrm{kHz}$ and an echo delay $(\tau)$ of $50 \mathrm{msec} .{ }^{*}$ The central peak was assigned to the isotropic peak of un-coordinated dabco.

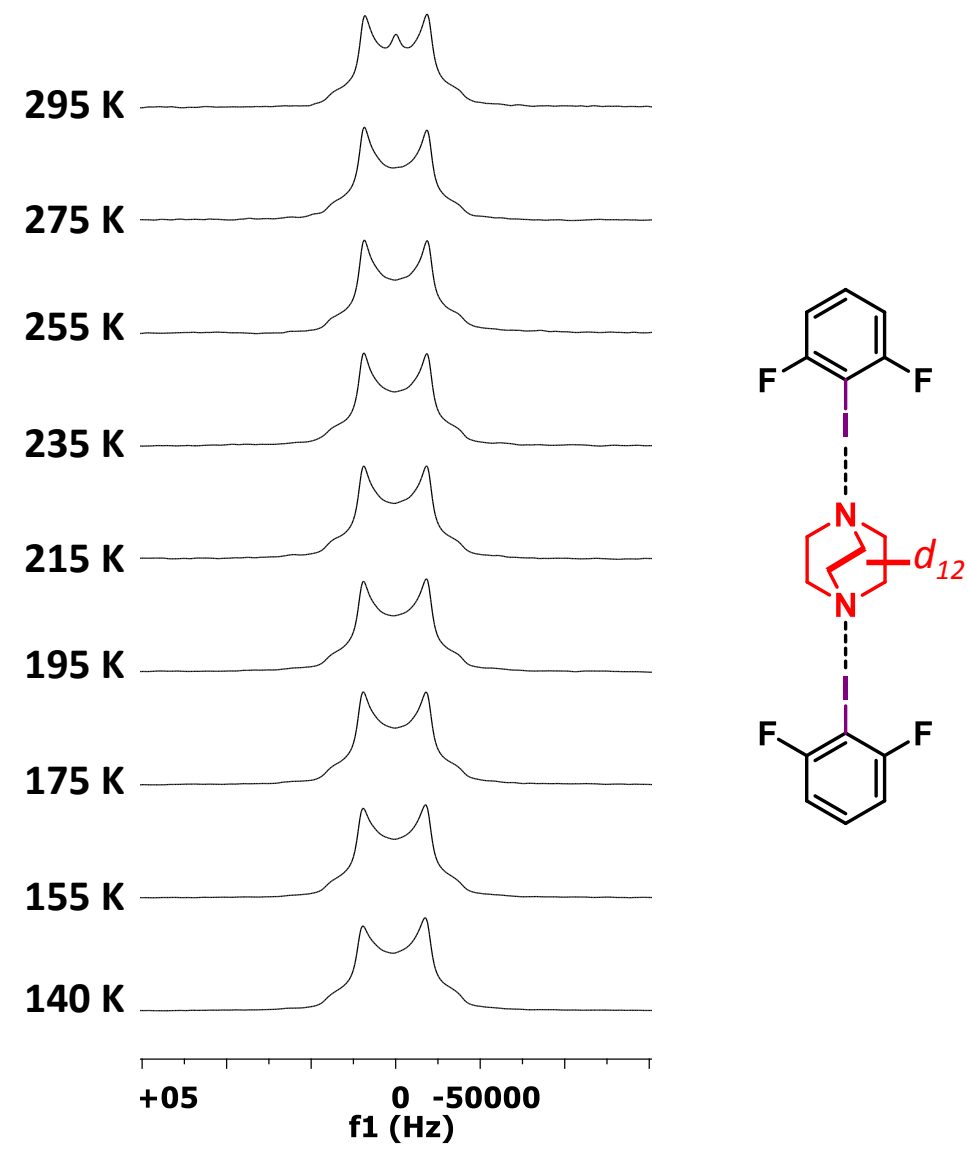

Figure S33. Variable temperature ${ }^{2} \mathrm{H}$ NMR quadrupolar echo experiments for complex $\mathrm{F}_{2} \mathrm{PhI} \cdot \mathrm{DABCO}-d_{12}\left(\mathbf{2 b}-\boldsymbol{d}_{12}\right)$ from $295 \mathrm{~K}$ to $140 \mathrm{~K}$. 

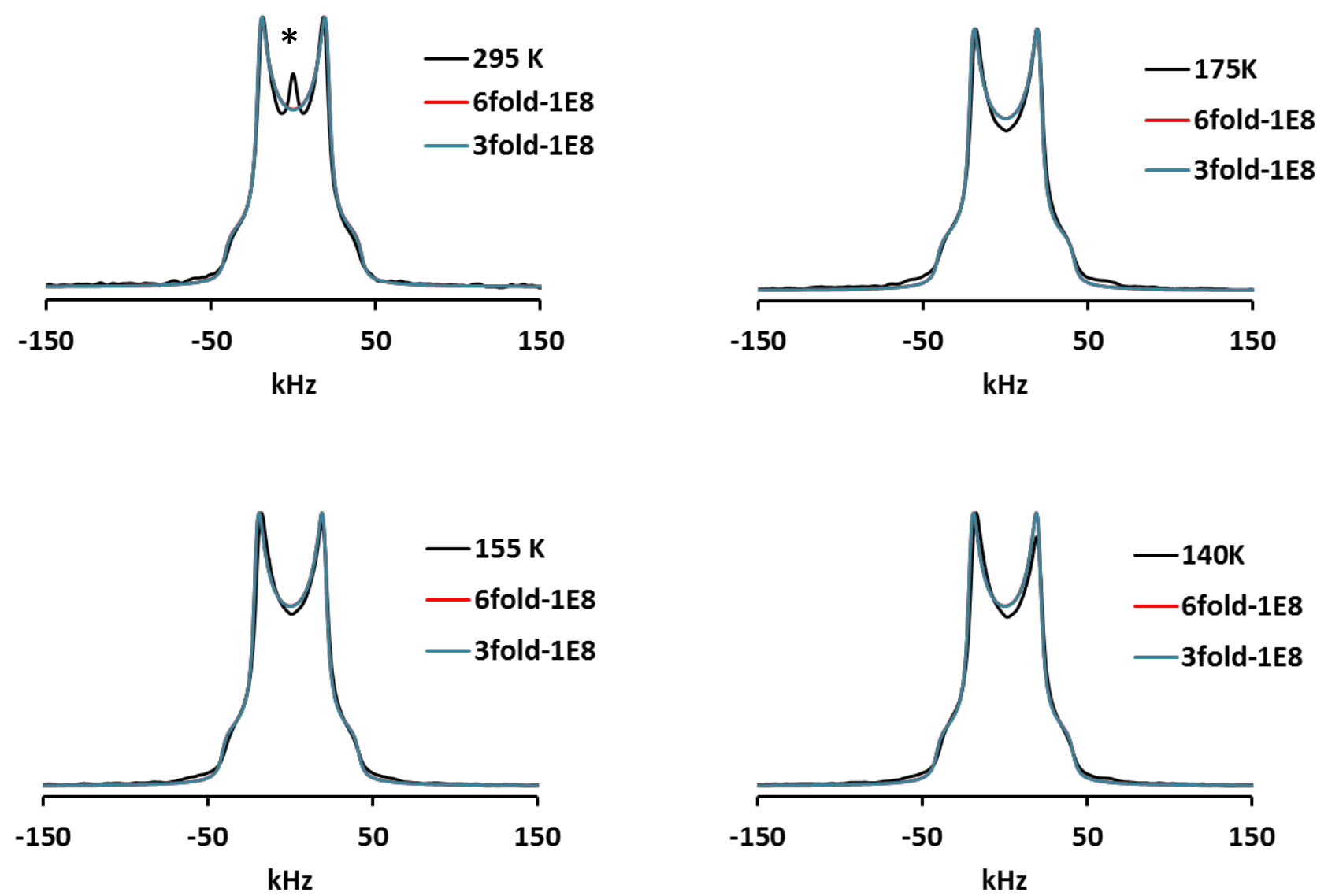

Figure S34. Experimental and simulated ${ }^{2} \mathrm{H}$ NMR quadrupolar echo spectra of $\mathbf{2 b}-\boldsymbol{d}_{\mathbf{1 2}}$. Simulations were carried out using the Nishikiori's program with a $\beta$ angle of $70^{\circ}$, a QCC of $170 \mathrm{kHz}$, a linebroadening of $5 \mathrm{kHz}$ and an echo delay $(\tau)$ of $50 \mathrm{msec}$. 


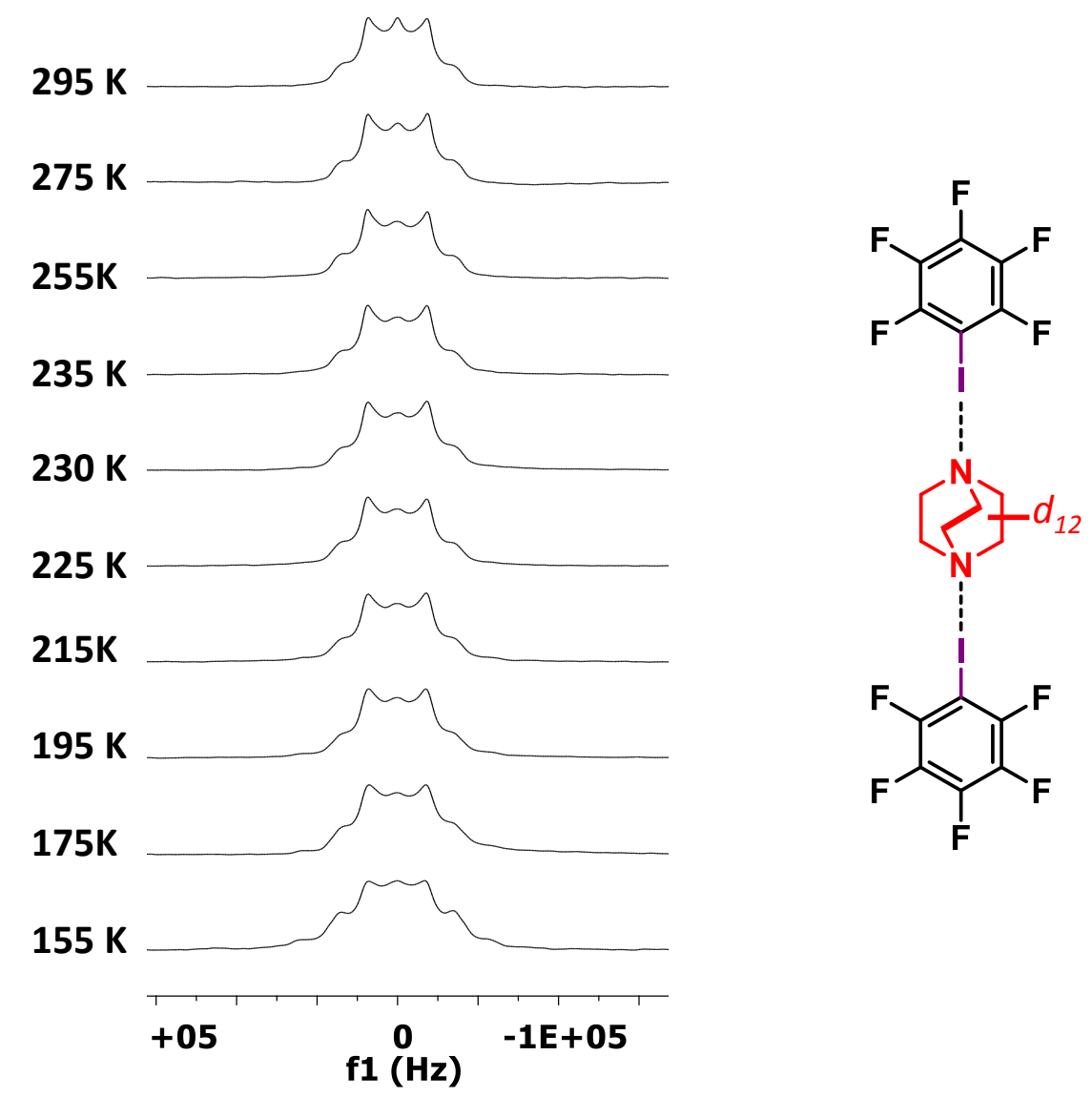

Figure S35. Variable temperature ${ }^{2} \mathrm{H}$ NMR quadrupolar echo experiments for complex $\mathrm{F}_{5} \mathrm{PhI} \cdot \mathrm{DABCO}-d_{12}\left(\mathbf{2 e}-\boldsymbol{d}_{12}\right)$ from $295 \mathrm{~K}$ to $155 \mathrm{~K}$. 

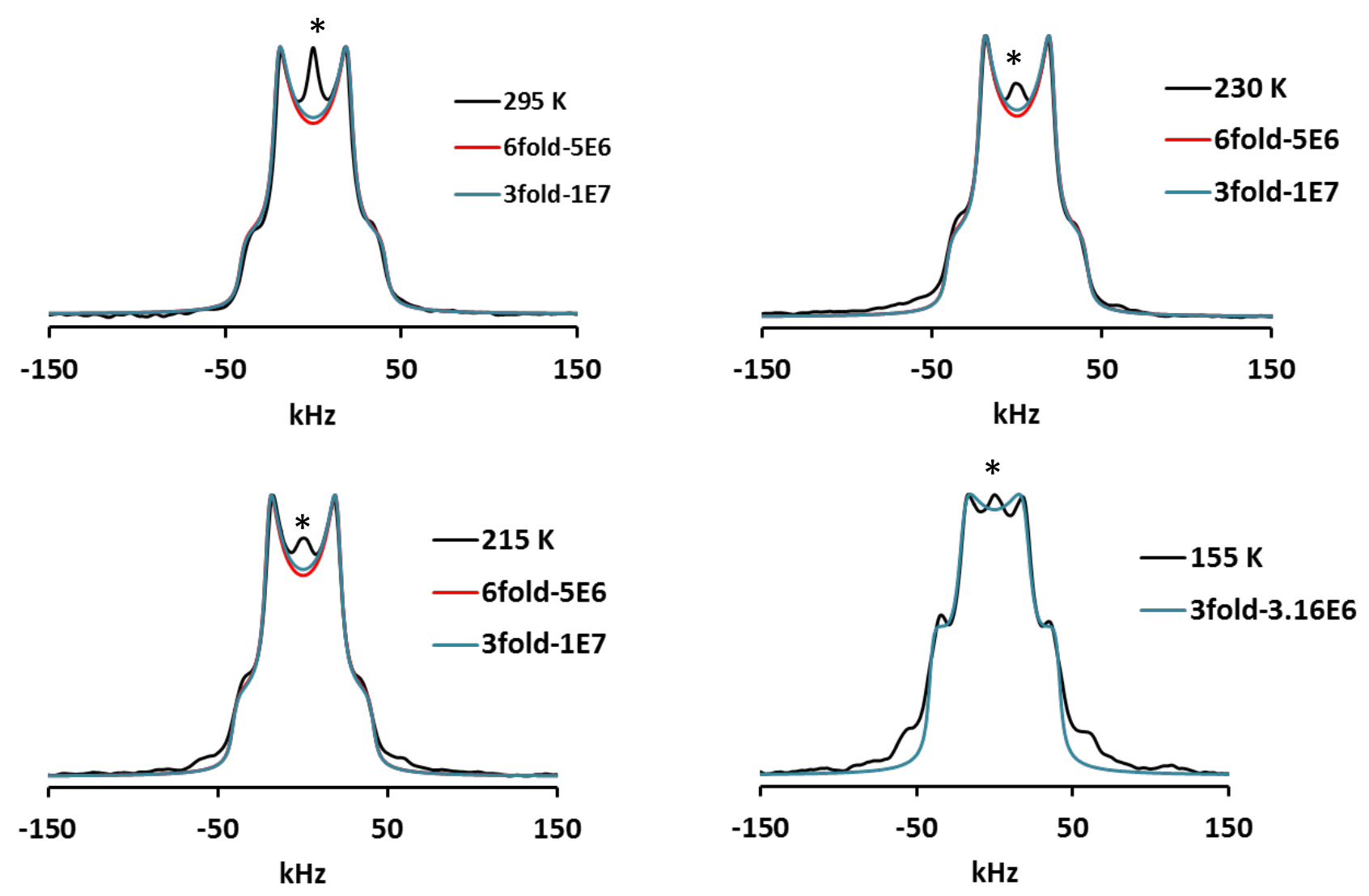

Figure S36. Experimental and simulated ${ }^{2} \mathrm{H}$ NMR quadrupolar echo spectra of $\mathbf{2 e}-\boldsymbol{d}_{\mathbf{1 2}}$. Simulations were carried out using the Nishikiori's program with a $\beta$ angle of $70^{\circ}$, a QCC of $170 \mathrm{kHz}$, a linebroadening of $5 \mathrm{kHz}$ and an echo delay $(\tau)$ of $50 \mathrm{msec}$. 
Table S2. Halogen bonding and hydrogen bonding geometrical features.

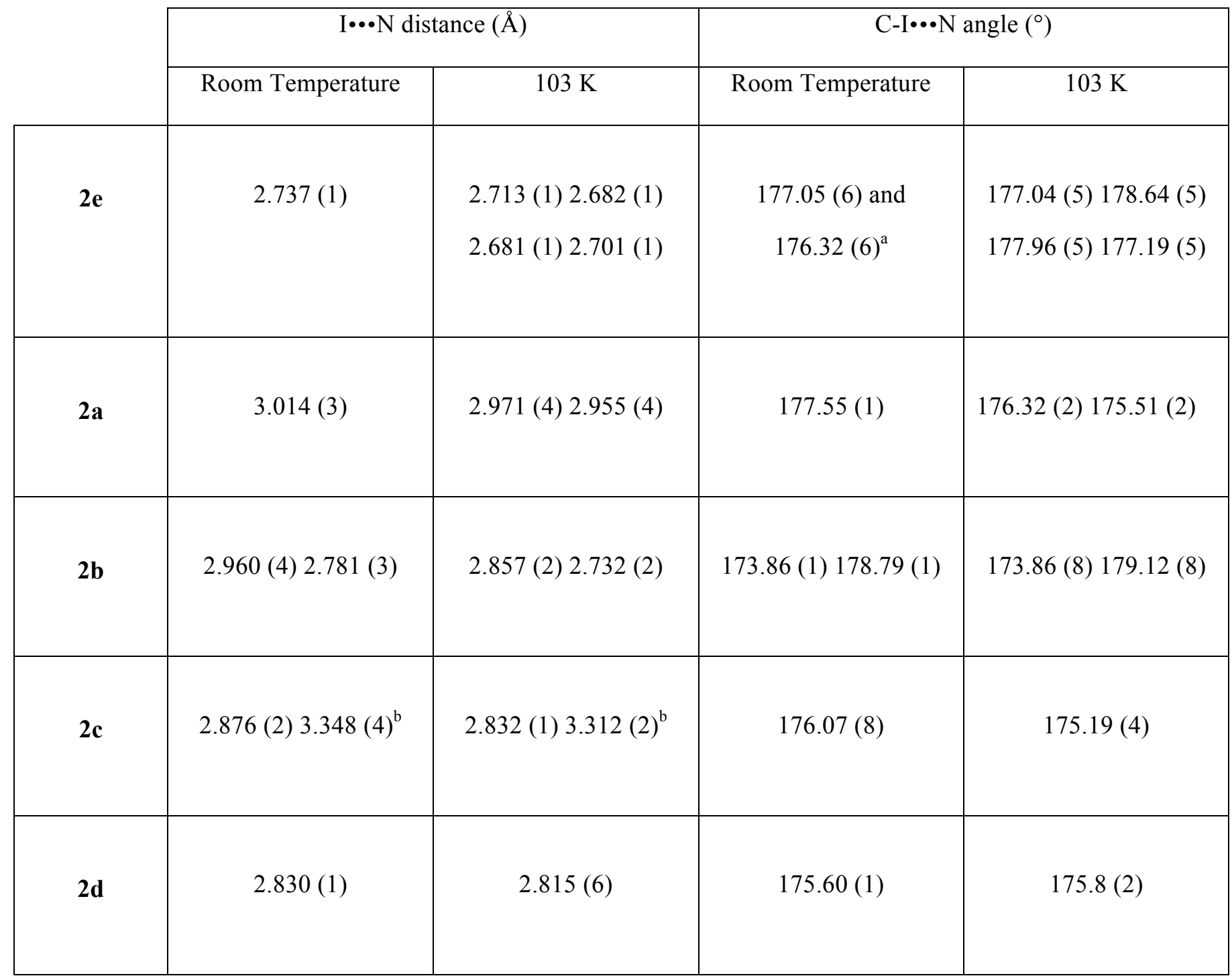

a The two angles refer to two disordered positions of the carbon bound to the iodine atom.

b The distances refer to $\mathrm{C}-\mathrm{H} \cdot \bullet \mathrm{N}$ hydrogen bond. The reported distances are between the $\mathrm{C}$ and $\mathrm{N}$, because the position of hydrogens is calculated. 


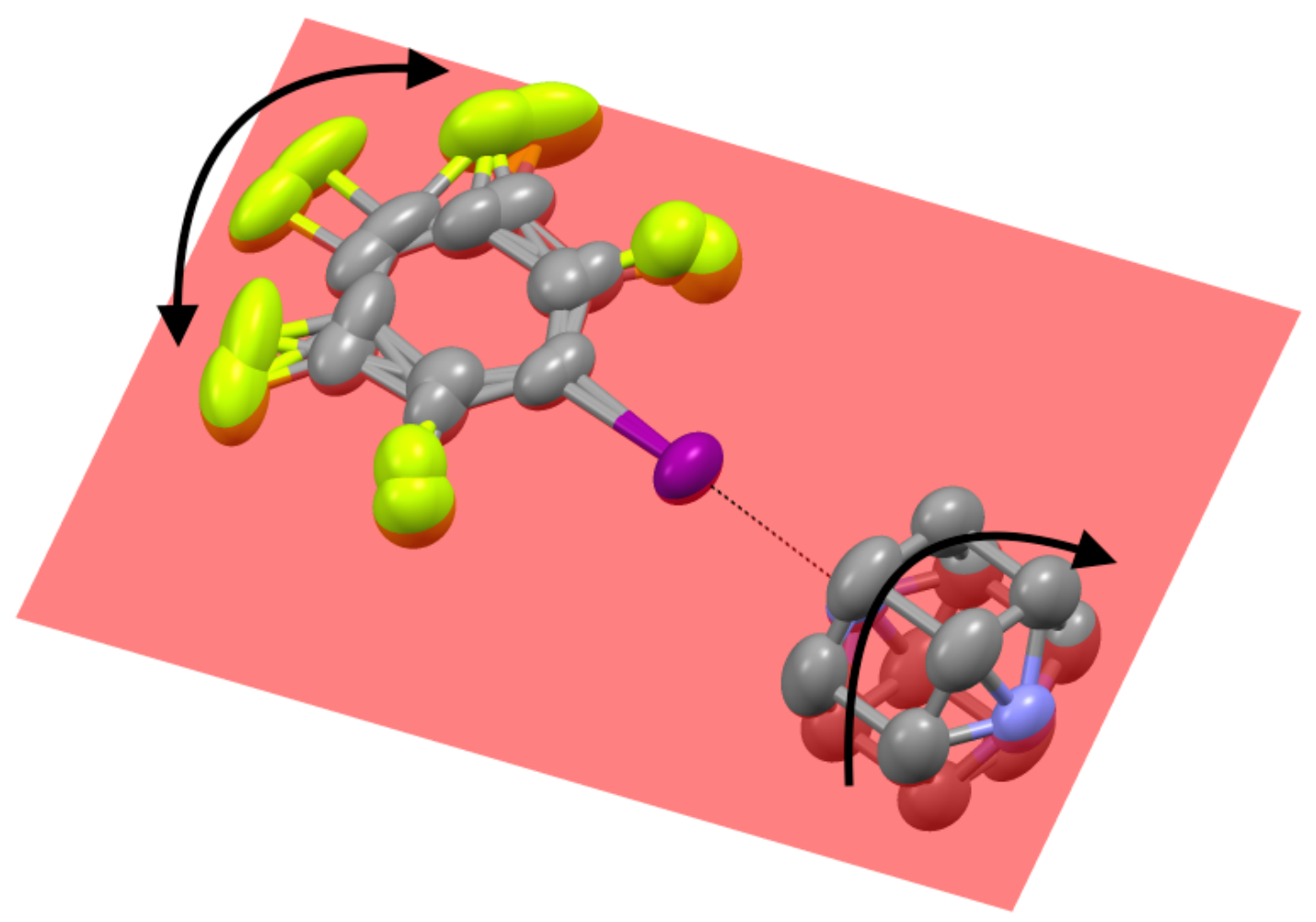

Figure S37. Asimmetric unit in 2e structure at Room Temperature. In red the benzene ring plane is highlighted. Looking at the pentafluoroiodobenzene thermal ellispoids and atoms splitted positions it is clear that the benzene derivative thermal motion is confined to one plane, thus the aromatic ring is not rotating as DABCO. 


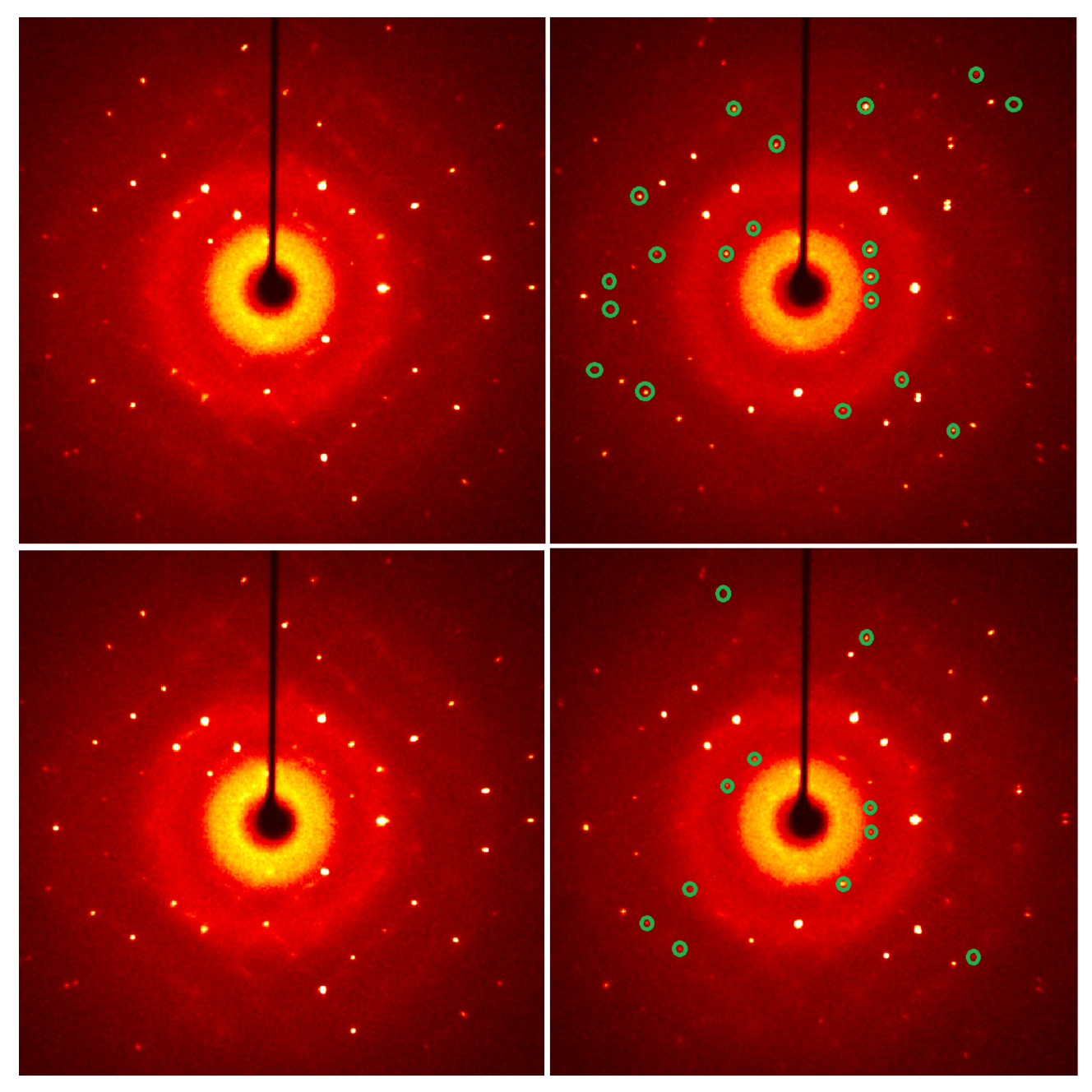

Figure S38. Procedure to follow the phase transitions of 2a and 2e. Four oscillating images of 2a lattice taken in a cooling-heating cycle around the phase transition temperature. Cooling: top-left at $280 \mathrm{~K}$; top-right at $270 \mathrm{~K}$. Heating; bottom-left at $280 \mathrm{~K}$; bottom-right at $279 \mathrm{~K}$. The immages are dramatically different and the appearance of reflections at $270 \mathrm{~K}$ (some of them circled in green), not compatible with the lattice at $280 \mathrm{~K}$, are a clear indication of the phase transition. 
Table S3. Crystallographic details of 2 e data collections at 7 different temperatures.

\begin{tabular}{|c|c|c|c|c|c|c|c|}
\hline Formula & $\begin{array}{l}2\left(\mathbf{C}_{6} \mathbf{F}_{5} \mathbf{I}\right) . \\
\mathbf{C}_{6} \mathbf{H}_{12} \mathbf{N}_{2}\end{array}$ & $\begin{array}{l}2\left(\mathbf{C}_{6} \mathbf{F}_{5} \mathbf{I}\right) . \\
\mathbf{C}_{6} \mathbf{H}_{12} \mathbf{N}_{2}\end{array}$ & $\begin{array}{l}2\left(\mathbf{C}_{6} \mathbf{F}_{5} \mathbf{I}\right) . \\
\mathbf{C}_{6} \mathbf{H}_{12} \mathbf{N}_{2}\end{array}$ & $\begin{array}{l}2\left(\mathbf{C}_{6} \mathbf{F}_{5} \mathbf{I}\right) . \\
\mathbf{C}_{6} \mathbf{H}_{12} \mathbf{N}_{2}\end{array}$ & $\begin{array}{l}2\left(\mathbf{C}_{6} \mathbf{F}_{5} \mathbf{I}\right) . \\
\mathbf{C}_{6} \mathbf{H}_{12} \mathbf{N}_{2}\end{array}$ & $\begin{array}{l}2\left(\mathbf{C}_{6} \mathbf{F}_{5} \mathbf{I}\right) . \\
\mathbf{C}_{6} \mathbf{H}_{12} \mathbf{N}_{2}\end{array}$ & $\begin{array}{l}2\left(\mathrm{C}_{6} \mathrm{~F}_{5} \mathbf{I}\right) . \\
\mathrm{C}_{6} \mathrm{H}_{12} \mathbf{N}_{2}\end{array}$ \\
\hline $\begin{array}{l}\text { Temperature } \\
\text { (K) }\end{array}$ & $297(2)$ & $250(2)$ & $220(2)$ & $200(2)$ & $180(2)$ & $140(2)$ & $103(2)$ \\
\hline System & monoclinic & monoclinic & monoclinic & monoclinic & monoclinic & monoclinic & monoclinic \\
\hline Space group & $P 2_{1} / c$ & $P 2_{1} / c$ & $P c$ & $P c$ & $P c$ & $P c$ & $P c$ \\
\hline$a(\AA)$ & $8.1331(2)$ & $8.1324(3)$ & $8.0881(3)$ & $8.0570(3)$ & $8.0353(4)$ & 7.9746(4)) & $7.9438(6)$ \\
\hline$b(\AA)$ & $10.6901(3)$ & $10.6494(4)$ & 21.1918(8) & $21.1290(7)$ & 21.0755(9)' & $20.9827(9)$ & $20.923(2)$ \\
\hline$c(\AA)$ & $13.1218(3)$ & $13.0939(5)$ & $13.0834(5)$ & $13.0753(5)$ & $13.0840(6)$ & $13.0699(6)$ & $13.0731(12$ \\
\hline$\alpha\left(^{\circ}\right)$ & 90.00 & 90.00 & 90.00 & 90.00 & 90.00 & 90.00 & 90.00 \\
\hline$\beta\left({ }^{\circ}\right)$ & $99.9680(10)$ & $99.702(2)$ & $99.594(2)$ & $99.567(2)$ & $99.573(2)$ & $99.5560(10$ & $99.508(6)$ \\
\hline$\gamma\left({ }^{\circ}\right)$ & 90.00 & 90.00 & 90.00 & 90.00 & 90.00 & 90.00 & 90.00 \\
\hline$V\left(\AA^{3}\right)$ & $1130.54(5)$ & 1117.78(7) & $2211.15(14$ & $2194.93(14$ & $2184.89(17$ & $2156.62(17$ & $2143.0(3)$ \\
\hline$Z$ & 2 & 2 & 4 & 4 & 4 & 4 & 4 \\
\hline Collected $I_{0}$ & 25913 & 23669 & 108261 & 56823 & 40089 & 38298 & 110604 \\
\hline Unique $I_{0}$ & 3169 & 2552 & 16172 & 15325 & 11882 & 14790 & 22443 \\
\hline$I_{0}>2 \sigma\left(I_{o}\right)$ & 2373 & 1909 & 8903 & 11620 & 10328 & 13602 & 21073 \\
\hline $\boldsymbol{R}_{\text {ave }}$ & 0.0257 & 0.0357 & 0.0421 & 0.0310 & 0.0276 & 0.0255 & 0.0255 \\
\hline Parameters & 272 & 271 & 908 & 772 & 578 & 578 & 578 \\
\hline Restraints & 333 & 321 & 1565 & 1037 & 2 & 2 & 2 \\
\hline$R_{1}\left[I_{o}>2 \sigma\left(I_{o}\right)\right]$ & 0.0216 & 0.0216 & 0.0372 & 0.0328 & 0.0309 & 0.0259 & 0.0201 \\
\hline$w R_{2}$ (all) & 0.0421 & 0.0421 & 0.0729 & 0.0621 & 0.0650 & 0.0454 & 0.0369 \\
\hline G.o.f. & 1.036 & 1.007 & 0.996 & 1.016 & 1.020 & 1.007 & 1.019 \\
\hline$\Delta \rho_{\min } \mathrm{e} \AA^{-3}$ & -0.28 & -0.29 & -0.54 & -0.55 & -0.46 & -0.41 & -0.57 \\
\hline$\Delta \rho_{\max } \mathrm{e} \AA^{-3}$ & 0.22 & 0.06 & 0.60 & 0.08 & 0.68 & 0.77 & 0.79 \\
\hline
\end{tabular}


Table S4. Crystallographic details of $\mathbf{2 b}$ and $\mathbf{2 c}$ data collections at different temperatures.

\begin{tabular}{|c|c|c|c|c|c|c|}
\hline & \multicolumn{3}{|c|}{ 2b } & \multicolumn{3}{|c|}{$2 c$} \\
\hline Formula & $\begin{array}{c}2\left(\mathrm{C}_{6} \mathbf{H}_{3} \mathbf{F}_{2} \mathbf{I}\right) \\
\mathbf{C}_{6} \mathbf{H}_{12} \mathbf{H}_{2}\end{array}$ & $\begin{array}{c}2\left(\mathrm{C}_{6} \mathbf{H}_{3} \mathbf{F}_{2} \mathbf{I}\right) \\
\mathbf{C}_{6} \mathbf{H}_{12} \mathbf{N}_{2}\end{array}$ & $\begin{array}{c}2\left(\mathbf{C}_{6} \mathbf{H}_{3} \mathbf{F}_{2} \mathbf{I}\right) \\
\mathbf{C}_{6} \mathbf{H}_{12} \mathbf{N}_{2}\end{array}$ & $\begin{array}{l}\mathbf{C}_{6} \mathbf{H}_{3} \mathbf{F}_{2} \mathbf{I} . \\
\mathbf{C}_{6} \mathbf{H}_{12} \mathbf{N}_{2}\end{array}$ & $\begin{array}{l}\mathbf{C}_{6} \mathbf{H}_{3} \mathbf{F}_{2} \mathbf{I} . \\
\mathbf{C}_{6} \mathbf{H}_{12} \mathbf{N}_{2}\end{array}$ & $\begin{array}{l}\mathbf{C}_{6} \mathbf{H}_{3} \mathbf{F}_{2} \mathbf{I} . \\
\mathbf{C}_{6} \mathbf{H}_{12} \mathbf{N}_{2}\end{array}$ \\
\hline Temperature (K) & $297(2)$ & $253(2)$ & $103(2)$ & $296(2)$ & $233(2)$ & $103(2)$ \\
\hline System & monoclinic & monoclinic & monoclinic & monoclinic & monoclinic & monoclinic \\
\hline Space group & $P 2_{1} / n$ & $P 2{ }_{1} / n$ & $P 2_{1} / n$ & $P 22_{1} / c$ & $P 2_{1} / c$ & $P 2{ }_{1} / c$ \\
\hline$a(\AA)$ & $6.6497(8)$ & $6.6438(8)$ & $6.6183(10)$ & $10.7720(10)$ & $10.7352(9)$ & $10.7007(6)$ \\
\hline$b(\AA)$ & $31.023(5)$ & $30.796(4)$ & $30.067(5)$ & $9.7608(8)$ & $9.6627(6)$ & $9.4853(5)$ \\
\hline$c(\AA)$ & $10.1247(8)$ & $10.1083(12)$ & $10.0093(16)$ & $13.4616(12)$ & $13.3970(12)$ & $13.2984(8)$ \\
\hline$\alpha\left(^{\circ}\right)$ & 90.00 & 90.00 & 90.00 & 90.00 & 90.00 & 90.00 \\
\hline$\beta\left({ }^{\circ}\right)$ & $95.124(8)$ & $93.656(9)$ & $93.56(2)$ & $99.003(6)$ & $99.145(10)$ & $99.438(4)$ \\
\hline$\gamma\left({ }^{\circ}\right)$ & 90.00 & 90.00 & 90.00 & 90.00 & 90.00 & 90.00 \\
\hline$V\left(\AA^{3}\right)$ & 2080.3(5) & $2064.0(4)$ & $1987.9(5)$ & $1398.0(2)$ & $1372.0(2)$ & 1331.51(13) \\
\hline $\boldsymbol{Z}$ & 4 & 4 & 4 & 4 & 4 & 4 \\
\hline Collected $I_{0}$ & 34482 & 36509 & 35159 & 20152 & 48399 & 54204 \\
\hline Unique $I_{0}$ & 3715 & 5307 & 6102 & 3198 & 5229 & 9283 \\
\hline$I_{0}>2 \sigma\left(I_{o}\right)$ & 2812 & 4458 & 5528 & 2270 & 319 & 7013 \\
\hline $\boldsymbol{R}_{\text {ave }}$ & 0.0320 & 0.0267 & 0.0358 & 0.0323 & 0.0347 & 0.0355 \\
\hline Parameters & 236 & 235 & 235 & 209 & 163 & 163 \\
\hline Restraints & 21 & 0 & 0 & 21 & 3 & 3 \\
\hline$R_{1}\left[I_{o}>2 \sigma\left(I_{o}\right)\right]$ & 0.0276 & 0.0301 & 0.0278 & 0.0236 & 0.0340 & 0.0271 \\
\hline$w R_{2}($ all $)$ & 0.0668 & 0.0776 & 0.0563 & 0.0614 & 0.0870 & 0.0581 \\
\hline G.o.f. & 1.014 & 1.049 & 1.187 & 1.009 & 0.992 & 1.006 \\
\hline$\Delta \rho_{\min } \mathrm{e} \AA^{-3}$ & -0.53 & -1.06 & -0.54 & -0.41 & -0.45 & -0.88 \\
\hline$\Delta \rho_{\max } \mathrm{e} \AA^{-3}$ & 0.46 & 0.66 & 0.66 & 0.37 & 0.68 & 1.28 \\
\hline
\end{tabular}


Table S5. Crystallographic details of $\mathbf{2 a}$ and $\mathbf{2 d}$ data collections at different temperatures.

\begin{tabular}{|c|c|c|c|c|c|}
\hline & \multicolumn{3}{|c|}{$2 a$} & \multicolumn{2}{|c|}{ 2d } \\
\hline Formula & $\begin{array}{c}2\left(\mathrm{C}_{6} \mathrm{H}_{4} \mathrm{FI}\right) \\
\mathrm{C}_{6} \mathrm{H}_{12} \mathrm{~N}_{2}\end{array}$ & $\begin{array}{c}2\left(\mathrm{C}_{6} \mathrm{H}_{4} \mathrm{FI}\right) \\
\mathrm{C}_{6} \mathrm{H}_{12} \mathrm{~N}_{2}\end{array}$ & $\begin{array}{c}2\left(\mathrm{C}_{6} \mathrm{H}_{3} \mathrm{~F}_{2} \mathrm{I}\right) \\
\mathrm{C}_{6} \mathrm{H}_{12} \mathrm{~N}_{2}\end{array}$ & $\begin{array}{l}\mathrm{C}_{6} \mathrm{H}_{2} \mathrm{~F}_{3} \mathbf{I} . \\
\mathrm{C}_{6} \mathrm{H}_{12} \mathbf{N}_{2}\end{array}$ & $\begin{array}{c}\mathrm{C}_{6} \mathrm{H}_{2} \mathrm{~F}_{3} \mathrm{I} \\
\mathrm{C}_{6} \mathrm{H}_{12} \mathrm{~N}_{2}\end{array}$ \\
\hline Temperature (K) & $297(2)$ & $270(2)$ & $103(2)$ & $296(2)$ & $100(2)$ \\
\hline System & monoclinic & triclinic & triclinic & monoclinic & monoclinic \\
\hline Space group & $C 2 / c$ & $P-1$ & $P-1$ & $P 2_{1} / c$ & $P 2_{1} / c$ \\
\hline$a(\AA)$ & $8.547(2)$ & $6.2187(9)$ & $6.0623(10)$ & $6.6529(6)$ & $6.5893(7)$ \\
\hline$b(\AA)$ & $9.334(2)$ & $12.6468(18)$ & $12.477(2)$ & $20.388(2)$ & $20.2195(19)$ \\
\hline$c(\AA)$ & $25.542(6)$ & $13.345(2)$ & $13.206(2)$ & $8.0414(8)$ & $7.9262(8)$ \\
\hline$\alpha\left(^{\circ}\right)$ & 90.00 & $73.611(9)$ & $74.566(15)$ & 90.00 & 90.00 \\
\hline$\beta\left({ }^{\circ}\right)$ & $94.81(2)$ & $78.799(7)$ & $78.334(9)$ & $102.832(4)$ & $102.405(5)$ \\
\hline$\gamma\left({ }^{\circ}\right)$ & 90.00 & $84.086(6)$ & $83.940(10)$ & 90.00 & 90.00 \\
\hline$V\left(\AA^{3}\right)$ & $1998.7(8)$ & $986.4(3)$ & $941.6(3)$ & $1063.49(18)$ & $1031.37(18)$ \\
\hline$Z$ & 4 & 2 & 2 & 2 & 2 \\
\hline Collected $I_{0}$ & 34118 & $*$ & 51341 & 21644 & 38735 \\
\hline Unique $I_{0}$ & 2907 & * & 8540 & 5676 & 2893 \\
\hline$I_{0}>2 \sigma\left(I_{o}\right)$ & 2207 & * & 7423 & 3684 & 2773 \\
\hline $\boldsymbol{R}_{\text {ave }}$ & 0.0830 & * & 0.0263 & 0.0262 & 0.0248 \\
\hline Parameters & 136 & $*$ & 217 & 155 & 190 \\
\hline Restraints & 0 & * & 0 & 0 & 93 \\
\hline$R_{I}\left[I_{o}>2 \sigma\left(I_{o}\right)\right]$ & 0.0398 & * & 0.0458 & 0.0265 & 0.0548 \\
\hline$w R_{2}$ (all) & 0.1086 & $*$ & 0.1512 & 0.0571 & 0.1336 \\
\hline G.o.f. & 1.081 & * & 1.258 & 1.005 & 1.540 \\
\hline$\Delta \rho_{\min } \mathrm{e}^{-3}$ & -0.982 & * & -2.372 & -0.845 & -1.427 \\
\hline$\Delta \rho_{\max } \mathrm{e}^{-3}$ & 1.366 & * & 2.290 & 0.610 & 1.273 \\
\hline
\end{tabular}

* Structure not refined due to bad quality crystals, high twinning. 
Figure S39. Halogen-bonded supramolecular trimers of 2a crystal lattice at $103 \mathrm{~K}$.

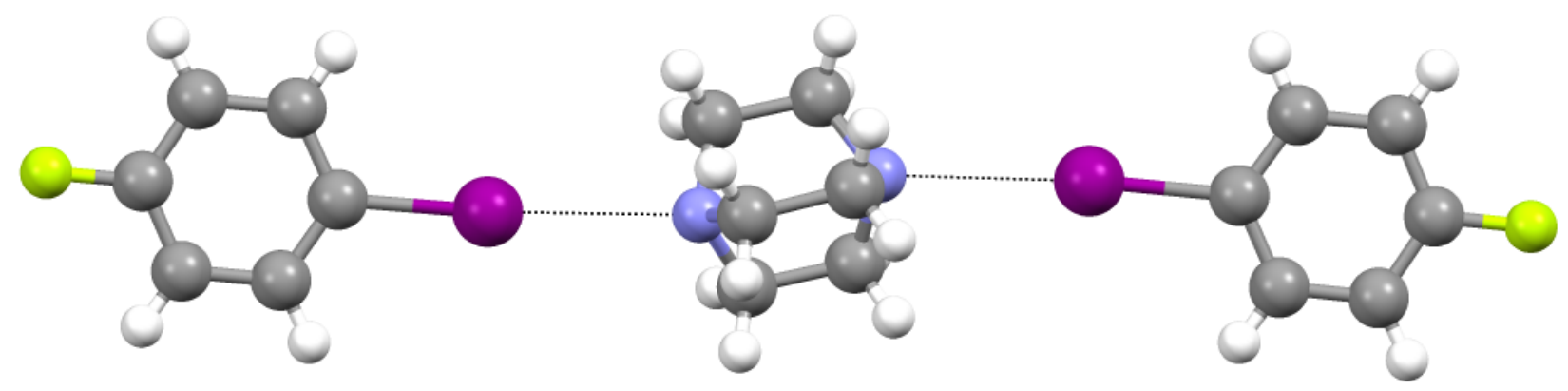

Figure S40. Halogen-bonded supramolecular trimers of $\mathbf{2 b}$ crystal lattice at $103 \mathrm{~K}$.

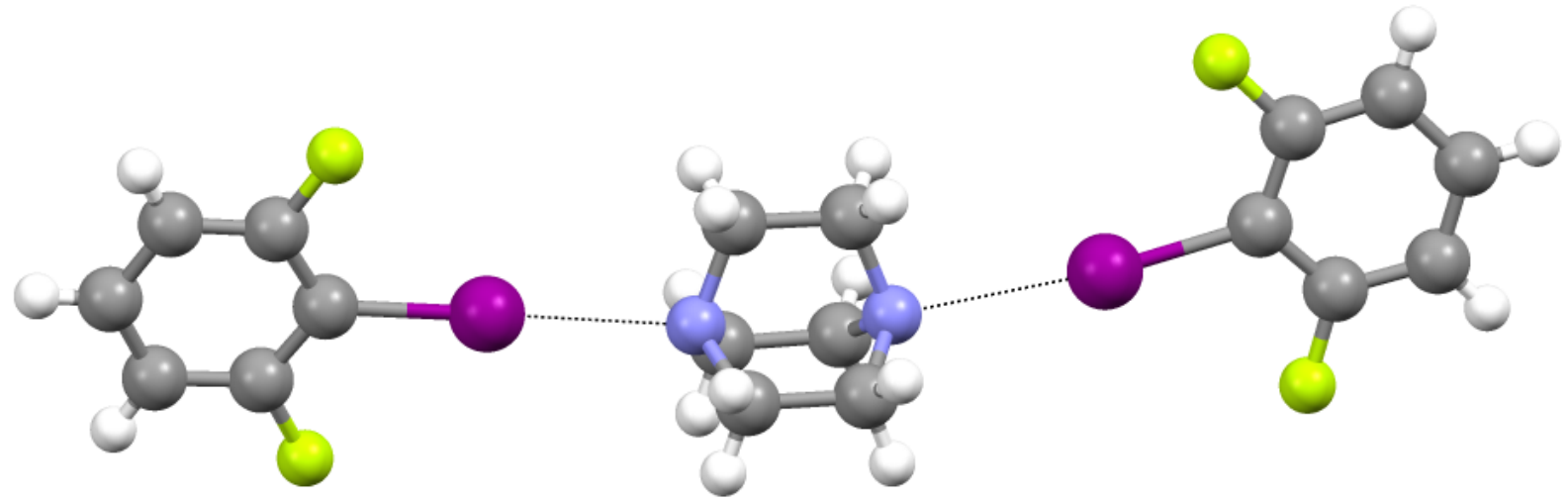

Figure S41. Halogen-bonded supramolecular trimers of $\mathbf{2 d}$ crystal lattice at $100 \mathrm{~K}$. As it is clear dabco molecules still display disorded positions at low temperature.

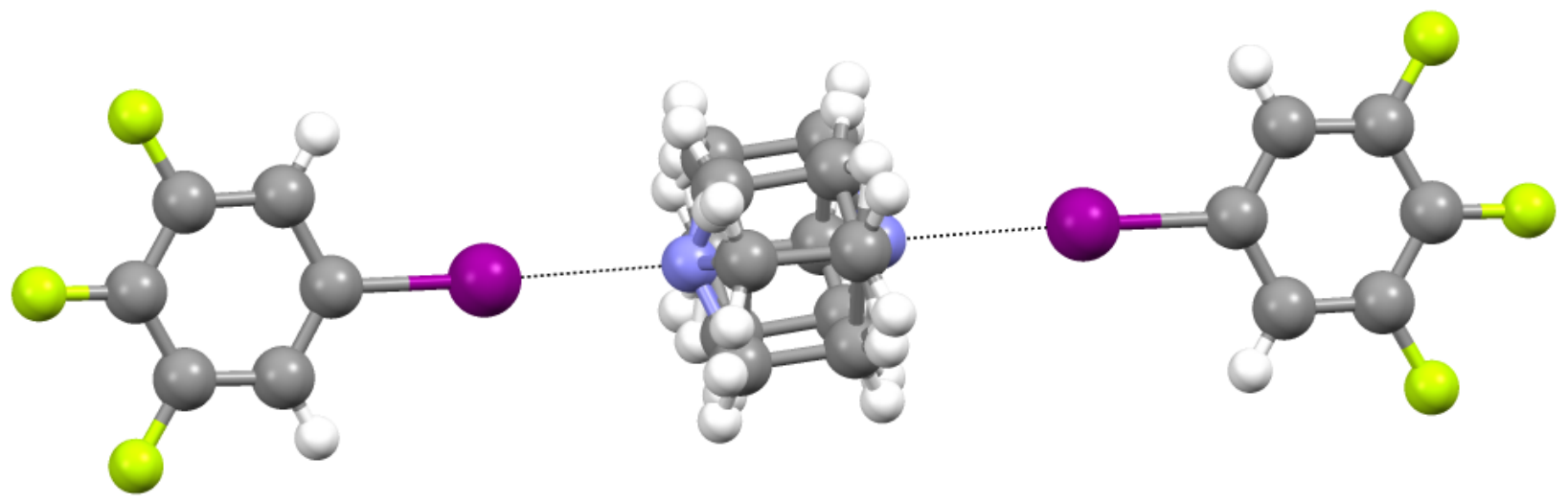

\section{References:}

[1] G.M. Sheldrick, Acta Crystallogr. Sect. A. 2008, 64, 112.

[2] C. F. Macrae, I. J. Bruno, J.A. Chisholm, P. R. Edgington, P.McCabe, E. Pidcock, L. Rodriguez-Monge, R. Taylor, J. van de Streek and P. A. Wood, J. Appl. Cryst. 2008, 41, 466. 